\title{
Solid State Magnetic Resonance Investigation of the Thermally-Induced Structural Evolution of Silicon Oxide-Doped Hydrogenated Amorphous Carbon
}

\author{
Jing Peng ${ }^{\mathrm{a}, \mathrm{b}}$, Anastasiia Sergiienko ${ }^{\mathrm{a}}$, Filippo Mangolini ${ }^{\mathrm{c}, *}$, Phillip E. Stallworth ${ }^{\mathrm{a}}$, Steve \\ Greenbaum $^{\mathrm{a}, \mathrm{b}}$, Robert W. Carpick ${ }^{\mathrm{d}}$
}

\footnotetext{
${ }^{\text {a }}$ Physics Department, Hunter College, New York, New York, NY 10065

${ }^{\mathrm{b}}$ Ph.D. Program in Chemistry, The Graduate Center of the City University of New York, New York, NY 10016

${ }^{\mathrm{c}}$ Institute of Functional Surfaces, School of Mechanical Engineering, University of Leeds, Leeds, LS2 9JT, UK

${ }^{\mathrm{d}}$ Department of Mechanical Engineering and Applied Mechanics, University of Pennsylvania, Philadelphia, PA 19104
}

\begin{abstract}
Due to their increased stability in extreme environments, relative to amorphous hydrogenated carbons (a-C:H), amorphous thin film silicon oxide-doped hydrogenated amorphous carbons (a-C:H:Si:O) are being commercially developed as solid lubricants and protective coatings. Although various properties of a-C:H:Si:O have been investigated, no definitive structure of a$\mathrm{C}: \mathrm{H}: \mathrm{Si}: \mathrm{O}$ has ever been proposed, nor has its thermally-induced structural evolution been thoroughly studied. The aim of this work is to better understand the structure of a-C:H:Si:O through solid-state nuclear magnetic resonance (NMR) and electron paramagnetic resonance (EPR) spectroscopies. Deeper insights into the thermally-driven structural evolution are obtained by annealing a-C:H:Si:O between $50^{\circ} \mathrm{C}$ and $300^{\circ} \mathrm{C}$ under anaerobic conditions and taking NMR/EPR measurements after each step. EPR results show that the number of paramagnetic defects decreases by $70 \%$ with annealing at $300{ }^{\circ} \mathrm{C}$. ${ }^{1} \mathrm{H}$ NMR shows the hydrogen concentration decreases with annealing temperature from $2 \times 10^{22} \mathrm{~g}^{-1}$, and then levels off at approximately $0.7 \times 10^{22} \mathrm{~g}^{-1}$ for anneals between $200^{\circ} \mathrm{C}$ and $300^{\circ} \mathrm{C}$. The carbon-silicon-oxygen network exhibits some structural reorganization, seen directly as a slight increase in the $s p^{2} / s p^{3}$ ratio in the ${ }^{13} \mathrm{C} \mathrm{NMR}$ with annealing. These results combined with relaxation data are interpreted according to a two-component structure largely defined by differences in hydrogen and defect contents.
\end{abstract}

\footnotetext{
${ }^{*}$ Corresponding author. Tel: +44-(0)113-343-9740. Email: f.mangolini@leeds.ac.uk
} 


\section{Introduction}

Amorphous materials are ubiquitous in nature and in synthetic systems [1]. In light of many unique mechanical, optical, magnetic, and electronic properties, they are attractive materials for current and emergent technologies, including photovoltaics, thin-film transistors, p-n diodes, light valves, spacecraft components, springs, biomedical implants, and energy-absorbing structures [1-4]. The structural characterization of amorphous solids constitutes a challenging materials science problem, since the lack of crystallinity in these materials hinders the use of diffraction methods, and the structures cannot be described by simple symmetry rules, nor do they form stable, well-defined low-energy configurations. Furthermore, while the chemical composition of these solids can be readily determined using standard analytical methods, such as energy dispersive spectroscopy or secondary ion mass spectroscopy, the investigation of the bonding configuration of the elements constituting the amorphous network is rather difficult due to the broad range of bond lengths and angles present. This inhibits the use of simple structural models, which are usually employed for investigating crystalline materials, for obtaining insights into the structure of amorphous solids.

Among the several amorphous materials that have been synthesized in the last decades, carbonbased materials have been used in a particularly wide range of technologically important applications thanks to their impressive properties, notably their high strength and strain to failure, ability to withstand harsh physical and chemical conditions, their ability to form smooth, continuous, ultra-thin, conformal coatings, as well as their outstanding tribological performance (i.e., low friction, wear, and adhesion) thus rendering them appealing as protective coatings and as solid lubricants $[5,6]$. The most well-known class of carbon-based materials for these applications is composed almost purely of amorphous carbon (a-C) and is usually referred to as diamond-like carbon (DLC). Thin-film a-C materials containing some hydrogen are usually referred to as amorphous hydrogenated carbon (a-C:H), and are typically grown by chemical or physical vapor deposition. The highly non-equilibrium conditions in these deposition methods result in the presence of carbon atoms in different hybridization states (mainly $s p^{3}$ and $s p^{2}$, with a small fraction of $s p$ ) [5, 7-10]. Depending on the growth method and precursors, hydrogen can be included in the disordered network with amounts ranging from less than 5 at.\% to about 50 at.\%. Hydrogen modification significantly affects the resulting physico-chemical properties, including optical gap, electrical resistivity, internal stresses, elastic moduli, strength, and tribological properties [9].

To achieve multifunctionality, as well as to boost existing properties or introduce new ones, the synthesis procedure of amorphous carbon-based materials can be tailored by introducing dopants or alloying elements [11]. Silicon oxide-doped hydrogenated amorphous carbon (a-C:H:Si:O), sometimes referred to as diamond-like nanocomposites (DLNs), are a particularly promising class of multicomponent carbon-based materials for several engineering applications because they may 
have a higher thermal stability compared to hydrogenated amorphous carbon. The composition of this material can vary depending on deposition method, precursors, and parameters (indeed, different compositions are commercially available), but it has been reported in several cases to be approximately $\left(\mathrm{CH}_{0.15}\right)_{0.7}\left(\mathrm{SiO}_{0.3}\right)_{0.3}$ [12]. As discussed below, the material in the present investigation substantially differs from this previously reported composition. It is well known that a-C:H, upon heating above $150^{\circ} \mathrm{C}$, undergoes degradation that starts with the out-diffusion of hydrogen and is followed by the conversion of $s p^{3}$ bonds to $s p^{2}$ at higher temperatures [13]. a$\mathrm{C}: \mathrm{H}: \mathrm{Si}: \mathrm{O}$ 's maintain very good tribological properties across a broader range of conditions and environments than a-C:H films. The structure of a-C:H:Si:Os films, although fully amorphous, has been proposed to consist of two interpenetrating, interbonded networks, one being a-C:H, and the other a silica glass $\left(\mathrm{SiO}_{x}\right)$ network [14]. Even though the interpretation of the two networks constituting a-C:H:Si:O, i.e., a-C:H and $\mathrm{SiO}_{x}$, has been postulated to be complete [12, 15], no definitive model for the bulk structure(s) of a-C:H:Si:O has been adopted, nor has the thermallyinduced evolution of its bulk structure been studied. This lack of knowledge inhibits developing a fundamental understanding of the mechanisms by which the excellent thermal stability and tribological performance of a-C:H:Si:O are achieved. To gain insights into the structure and composition of DLCs, some of the most powerful tools in the material characterization arsenal have been used, including Raman spectroscopy [9, 16-19], X-ray photoelectron spectroscopy (XPS) [13, 20, 21], near edge X-ray absorption fine structure (NEXAFS) spectroscopy [22-24], electron energy loss spectroscopy (EELS) [25], Fourier-transform infrared spectroscopy (FT-IR) [26], X-ray reflectivity (XRR) [25], forward recoil elastic scattering (FRES) [27], nuclear magnetic resonance (NMR) spectroscopy [27-41], and electron paramagnetic resonance (EPR) spectroscopy [42-46]. Among them, the most direct analytical techniques that allow for quantitative structural characterization of DLCs are NMR and EPR spectroscopies.

The power of solid state NMR spectroscopy for the determination of the bonding configuration of carbon in DLCs derives from the presence of two well-separated, resolvable peaks in ${ }^{13} \mathrm{C}$ NMR spectra, as confirmed by ab initio calculations [47]. Pan et al. [39], Golzan et al. [34] and Jäger et al. [36] effectively employed NMR spectroscopy for gaining insights into the carbon hybridization states in sputtered a-C and tetrahedral amorphous carbon (ta-C). Besides providing information about the carbon hybridization state, NMR can also be used for investigating the evolution of the local structure of ta-C upon annealing [28, 29]: for example, on the basis of the peak lineshape and width, Alam et al. concluded that the reordering of $s p^{2}$ - and $s p^{3}$-bonded carbon atoms, rather than rehybridization from fourfold- to threefold-coordinated carbon, which is known to occur at much higher temperatures, is the mechanism leading to stress relaxation in ta- $\mathrm{C}$ upon annealing. The availability of high-power proton decoupling (HPDEC) and cross-polarization magic-angle 
spinning (CP-MAS) methods in NMR spectroscopy [27, 30-32, 37, 40, 41] and also EPR [43, 45] has enabled a thorough structural characterization of hydrogenated amorphous carbon (a-C:H) materials as well as DLC and Si-DLC films [27, 35, 44].

This present work is an effort to better understand the structure of as-deposited a-C:H:Si:O and its evolution upon annealing at moderate temperatures. Generally, the structural evolution of a-C:H occurs via: passivation of defects/mending of broken bonds, diffusion/effusion of hydrogen, carbon $s p^{3}$ to $s p^{2}$ conversion, and clustering and ordering of $s p^{2}$ hybridized carbon atoms. Some questions have been answered regarding the energetics of these processes [13, 48], but several questions remain concerning the interdependence of these phenomena on each other. This is the first report on the thermally-induced evolution (via annealing performed between $20^{\circ} \mathrm{C}$ and $300^{\circ} \mathrm{C}$ ) of the structure of a-C:H:Si:O as ascertained through a combination of NMR and EPR. ${ }^{1} \mathrm{H},{ }^{13} \mathrm{C}$, and ${ }^{29} \mathrm{Si} \mathrm{NMR}$ is used for the quantitative determination of the distributions of $s p^{3}$ - and $s p^{2}$-bonded carbon, the concentration of hydrogen, and to some lesser extent the bonding state of $\mathrm{Si}$ in the as-grown film. EPR spectroscopic analyses were carried out to investigate the number density of unpaired electron spins (dangling-bond defects).

\section{Experimental}

\subsection{Preparation of a-C:H:Si:O film}

Silicon oxide-doped hydrogenated amorphous carbon (a-C:H:Si:O) coatings were deposited on aluminum foils by Sulzer-Metco Inc. (Amherst, NY, USA) using a proprietary plasma-enhanced chemical vapor deposition (PECVD) process, whose details are described elsewhere [49-57]. Briefly, a plasma discharge was formed from a proprietary siloxane precursor by means of a hot filament, whose temperature ranged between 2073 K and 2273 K. During the deposition, a negative radio frequency (RF) bias voltage between -300 and $-500 \mathrm{~V}$ was applied to the substrate. Although the substrate temperature was not deliberately increased during the deposition process, the nearsurface region could increase due to ion impingement; the temperature rise is expected to be no more than $200 \mathrm{~K}$ above room temperature. The thickness of the a-C:H:Si:O coating was $2 \mu \mathrm{m}$. The chemical composition of the films was: $[\mathrm{C}]=57 \pm 3$ at. $\%$; $[\mathrm{O}]=3 \pm 1$ at. $\%$; $[\mathrm{Si}]=6 \pm 1$ at. $\%$; $[\mathrm{H}]=$ $34 \pm 3$ at.\%, measured by Rutherford backscattering spectrometry (RBS) and hydrogen forward scattering (HFS) spectrometry (Evans Analytical Group, Sunnyvale, CA, USA). The composition of this a-C:H:Si:O material is different from the one reported for some similar films in the literature, $\left(\mathrm{CH}_{0.15}\right)_{0.7}\left(\mathrm{SiO}_{0.3}\right)_{0.3}$ [12]. This difference likely derives simply from the use of different deposition 
conditions (e.g., chemistry of the precursors, parameters such as substrate bias voltage). The film density, determined by X-ray reflectivity, was $1.8 \pm 0.1 \mathrm{~g} / \mathrm{cm}^{3}$.

The a-C:H:Si:O films were removed from the substrate by dissolving the aluminum foil in a $25 \% \mathrm{v} / \mathrm{v}$ solution of hydrochloric acid ( $\mathrm{HCl}$, Fisher Scientific). Etching the aluminum substrate left flakes of a-C:H:Si:O films, which were then filtered from the solution, washed with distilled water (Fisher Scientific), and dried with nitrogen. The chemical etching of the aluminum substrate did not affect the surface chemistry and structure of a-C:H:Si:O, as indicated by control XPS and NEXAFS experiments (not shown).

\subsection{Annealing Experiments}

The hydrogen concentration $\left(N_{H}\right)$, paramagnetic content $\left(N_{S}\right)$, and carbon $s p^{2}$ and $s p^{3}$ fractions were monitored stepwise by examining samples of as-prepared a-C:H:Si:O heated to $50^{\circ} \mathrm{C}$ and subsequently to $100^{\circ} \mathrm{C}$ in a nitrogen atmosphere for $14 \mathrm{~h}$ using a Büchi model B-580 glass oven. The oven enclosure was initially evacuated by rough pumping to $\sim 88 \mathrm{kPa}$ then backfilled with $\mathrm{N}_{2}$ gas at standard pressure prior to the heat treatments. Since the initial assumption was that the material contained an intrinsic proton concentration of 'fixed' hydrogen along with a more volatile hydrogen component (i.e., unbound molecular species), it was necessary to perform the EPR and NMR measurements after driving off any ambient water and superficial hydrocarbon impurities. To follow any further $\mathrm{H}_{2}$ effusion, the sample was subsequently annealed at $150^{\circ} \mathrm{C}, 200^{\circ} \mathrm{C}$ and $300^{\circ} \mathrm{C}$ for $14 \mathrm{~h}$. EPR and NMR measurements were carried out under $\mathrm{N}_{2}$ gas and at room temperature after each heating period.

\subsection{Characterization}

\subsubsection{Electron Paramagnetic Resonance (EPR) Spectroscopy}

EPR measurements were performed on a Bruker EMX electron paramagnetic resonance spectrometer operating at X-band $(9.74 \mathrm{GHz}$ continuous wave, field swept). Small amounts of a$\mathrm{C}: \mathrm{H}: \mathrm{Si}: \mathrm{O}(\sim 1 \mathrm{mg})$ were placed at the bottom of quartz EPR tubes and measured at ambient lab temperature $\left(\sim 20^{\circ} \mathrm{C}\right)$. Spectra were acquired with $100 \mathrm{kHz}$ field modulation, $0.25 \mathrm{~mW}$ microwave power, 3.00 Gauss modulation amplitude, $20.48 \mathrm{~ms}$ time constant, and $81.92 \mathrm{~ms}$ conversion time. The choice of modulation amplitude was guided by several considerations, mainly to obtain sufficient signal to noise in one scan without significantly distorting the EPR lineshape. In cases where changes in linewidth were observed under annealing, spectra acquired with smaller modulation amplitude were checked but not found to differ substantially from the ones shown later. Under these experimental conditions EPR signals exhibited no saturation. In order to ascertain the unpaired spin density in a-C:H:Si:O from the EPR spectra, a calibration was made using 4-hydroxy- 
TEMPO $\left(\mathrm{C}_{9} \mathrm{H}_{18} \mathrm{NO}_{2}\right.$ 4-hydroxy-2,2,6,6-tetramethylpiperidin-1-oxyl). TEMPO signal intensities (integrals of absorption spectra) were plotted versus number of radical TEMPO units, and the calibration (EPR signal intensity/spin) was obtained from the slope. Calibration samples were made using $0.02,0.04,0.06 \mathrm{ml}$ aliquots of a freshly prepared 0.026 M TEMPO/toluene solution.

\subsubsection{Nuclear Magnetic Resonance (NMR) Spectroscopy}

${ }^{1} \mathrm{H}$ NMR spectra were for the most part recorded at $300 \mathrm{MHz}$ using a ${ }^{1} \mathrm{H}$-free static probe. A spin-echo pulse sequence ( $\pi / 2-\tau-\pi-\tau-$ acquire) was employed to record these data where: $\pi / 2$ $=4.75 \mu \mathrm{s}, \tau=15 \mu \mathrm{s}$ to $5 \mathrm{~ms}$, with a recycle delay of $4 \mathrm{~s}$. Spin-spin relaxation times $\left(T_{2}\right)$ were extracted from these data, whereas a saturation-recovery sequence was used to obtain spin-lattice relaxation profiles $\left(T_{1}\right)$. The absolute number of protons in the sample $\left(N_{H}\right)$ was obtained through comparison with results from known quantities of standard materials, i.e., glycine or polymethylmethacrylate, etc. The hydrogen content calibration $\left({ }^{1} \mathrm{H}\right.$ NMR intensity per proton, $\left.I_{\text {proton }}\right)$ was determined by: 1) obtaining a set of static ${ }^{1} \mathrm{H}$ spin-echo spectra with respect to (w.r.t.) pulse separation (i.e., $\tau=$ echo dephasing time in the CPMG method [58] for substances with a known hydrogen content; 2) integrating these spectra; 3) plotting the natural $\log$ of the integrals w.r.t. $\tau$ to get the intercept, $\ln \left[I_{c}(\tau=0)\right]$; and 4) using this $I_{c}(0)$ to obtain the NMR signal intensity per proton ( $I_{\text {proton }}=I_{c}(0) \div$ \#protons in reference). $N_{H}$ is therefore obtained by first measuring the sample echo signal $I(\tau)$. The absolute intensity, $I(0)$, which cannot be measured directly, is extrapolated from a bi-exponential fitting function (eqn. 1 , see below). The final value for $N_{H}$ is obtained by dividing $I(0)$ by the calibration and sample mass, $N_{H}=\left[I(0) \div\left(I_{\text {proton }} \times\right.\right.$ mass $\left.)\right]$.

${ }^{13} \mathrm{C}$ magic angle spinning (MAS) NMR measurements were carried out on a Varian Inova solid state NMR spectrometer operating near $125 \mathrm{MHz}(11.8 \mathrm{~T})$ using a $4.0 \mathrm{~mm}$ DOTY MAS probe and silicon nitride rotors. In order to minimize background ${ }^{13} \mathrm{C}$ and ${ }^{1} \mathrm{H}$ NMR signals, the probe was modified, as practical, by removal of flourinated plastics (PTFE, Teflon) and hydrogen-containing plastics, epoxies and fabrics. ${ }^{13} \mathrm{C}$ chemical shifts are given relative to tetramethylsilane (TMS, $\left.\left(\mathrm{CH}_{3}\right)_{4} \mathrm{Si}\right)$, whose position is set to $0 \mathrm{ppm} .{ }^{13} \mathrm{C}$ NMR data were collected using a spin-echo pulse sequence, where the pulse parameters were: $\pi / 2=5 \mu \mathrm{s}, \tau=62.5 \mu \mathrm{s}(=1 / 16 \mathrm{kHz}$ for rotosynchronization). As a practical matter for acquiring spectra, shorter excitation pulses were used (i.e., $3 \mu \mathrm{s}$ ) to reduce the signal saturation limit and to improve the excitation bandwidth. Using these parameters, no significant differences in signal strength were observed with recycle delays greater than 7 s. ${ }^{13} \mathrm{C}$ MAS NMR spectra of a-C:H:Si:O samples are similar to those observed previously for amorphous hydrogenated carbon films [27, 29, 32, 41]. The isotropic chemical shift ranges are well known for the carbon $s p^{2}$ site (105 to $145 \mathrm{ppm}$ ) and $s p^{3}$ site (30 to $70 \mathrm{ppm}$ ), and their spectral components can be integrated to give the relative concentration of carbon hybridizations [27, 30, 
32, 33, 37, 41]. ${ }^{13} \mathrm{C}$ spin-lattice relaxation times $\left(T_{1}\right)$ were measured using a saturation recovery method with echo detection: $[\pi / 2-]_{n}-\tau_{\text {rec }}-\pi / 2-\tau-\pi-\tau$-acquire, where $n=25$ was chosen for complete signal saturation and $10 \mathrm{~ms}<\tau_{\text {rec }}<10 \mathrm{~s} .{ }^{13} \mathrm{C}$ CP-MAS can give insight into dipolar couplings between ${ }^{13} \mathrm{C}$ nuclei and nearby protons. For these measurements a suitable HartmannHahn match was obtained using a proton $\pi / 2$-pulse of $4 \mu$ s and spinning speed of $8.5 \mathrm{kHz}$. A recycle delay of $3.5 \mathrm{~s}$ was sufficient to prevent signal saturation and about 13000 scans were accumulated for reasonable signal-to-noise. In order to gauge the strength of the interactions, the contact time was varied between $500 \mu$ s and $6 \mathrm{~ms}$. Two samples were studied by CP: unannealed (as-prepared) a-C:H:Si:O and a-C:H:Si:O annealed at $50^{\circ} \mathrm{C}$ for $14 \mathrm{~h}$.

${ }^{29} \mathrm{Si}$ NMR measurements were carried out at $60 \mathrm{MHz}(7.1 \mathrm{~T})$ using a Varian/Chemagnetics 3.2 mm MAS probe (zirconia rotors) with a spinning rate of $20 \mathrm{kHz} .{ }^{29} \mathrm{Si}$ chemical shifts are also given relative to TMS (i.e., $\left.\left(\mathrm{CH}_{3}\right)_{4} \mathrm{Si}\right)$. Echos were collected using a spin-echo pulse sequence $(\pi / 2-\tau-\pi-$ $\tau$-acquire) with $\pi / 2=4 \mu \mathrm{s}, \tau=50 \mu \mathrm{s}$ (= $1 / 20 \mathrm{kHz}$ for rotosynchronization). Due to the very low signal strength (even upon acquiring data for about 18000 scans), no comprehensive ${ }^{29} \mathrm{Si}$ spinlattice relaxation measurements were performed. However, a recycle delay of $3.5 \mathrm{~s}$ appeared to be sufficient for the prevention of signal saturation. ${ }^{29} \mathrm{Si} \mathrm{CP}-\mathrm{MAS}$ was performed on the as-prepared a-C:H:Si:O sample with a spinning rate of $7.4 \mathrm{kHz}$ and ${ }^{1} \mathrm{H} \pi / 2$ of $4 \mu \mathrm{s}$. For these $\mathrm{CP}$ experiments roughly 5100 scans were accumulated.

\section{Results}

\subsection{EPR}

The primary objectives of this study are to use isotropic shifts, spin counts and relaxation data to gain insights into the structural changes that occur within a-C:H:Si:O films due to lowertemperature annealing. Any structural picture must take account of $s p^{2}$ and $s p^{3}$ hybridized carbon, as well as hydrogen content and defects. Broken bond structural defects in a-C:H:Si:O materials are associated with unpaired electronic spins, which can be monitored by EPR. The right side of Figure 1 displays the EPR spectrum for a-C:H:Si:O. This and the other single-featured EPR spectra gathered after annealing were centered near $g=2.0039$ with peak-to-antipeak linewidths of about 4 $\mathrm{G}$ to $4.5 \mathrm{G}$. The fact that the spectra are relatively narrow with no additional discernable features, suggests that the resonances are not indicative of strong hyperfine interactions with protons or transition metal impurities. The powder pattern spectra do not display anisotropy, if at all present, most likely because of strong homogeneous paramagnetic dipolar distributions present in the material. 

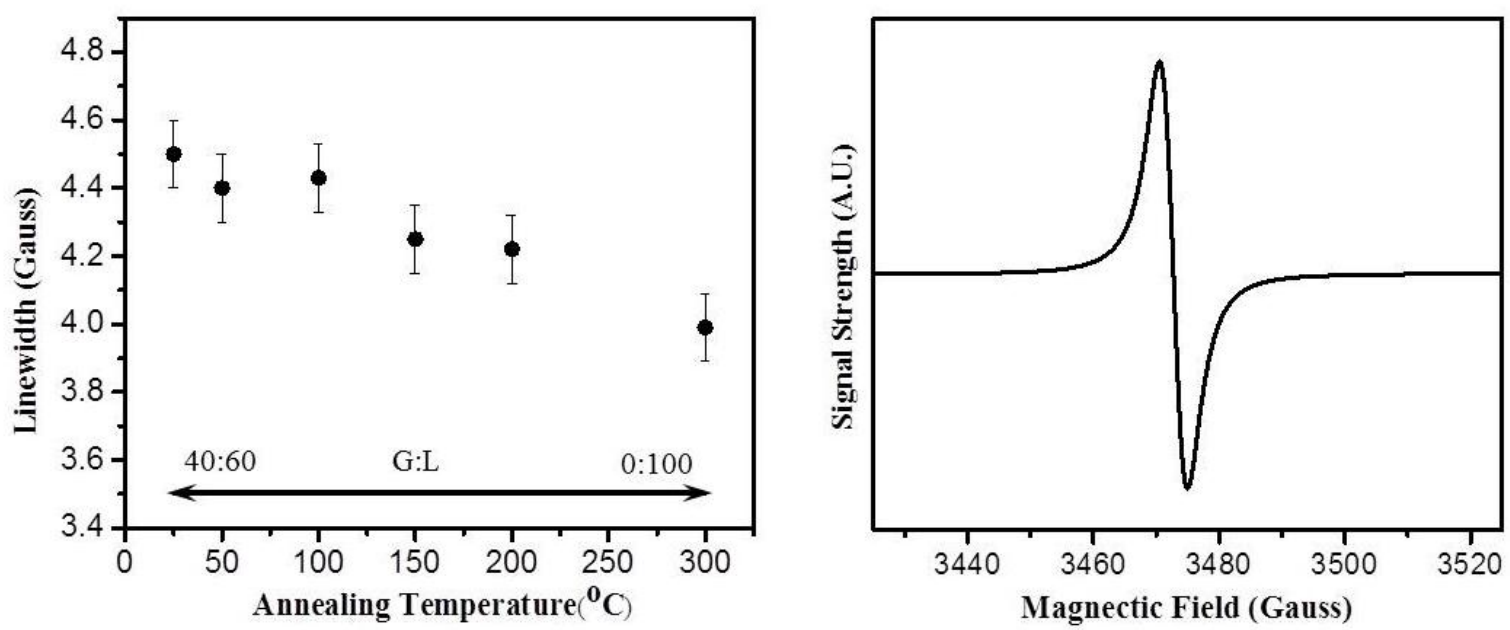

Figure 1. EPR spectrum for the as-prepared a-C:H:Si:O sample (right), and the peak-to-antipeak linewidth (G) w.r.t. annealing temperature (left). The Voigt EPR line shape description is indicated by the bar insert, from 40:60 (G:L) to purely Lorentzian 0:100 (L).

Upon annealing, peak positions did not vary (within experimental uncertainty), although linewidths decreased by about 10\% (left side of Figure 1). The lineshape, initially Voigt-like (convoluted by 40:60 Gaussian to Lorentzian contributions), became increasingly Lorentzian to almost $100 \%$ upon annealing at $200^{\circ} \mathrm{C}$ and $300^{\circ} \mathrm{C}$. These empirical differences mark substantial changes within the defect distribution as the material evolves. For example, a non-uniform distribution resulting in clustering could be related to the Gaussian character of the lineshape through enhanced spin-spin coupling. The $g$-value, being very much toward the high end of the typical range associated with thin-film hydrogenated amorphous carbons, indicates the resonance is more likely the result of a distribution of unpaired electrons in primarily broken non-graphitic carbon bond defects $[9,33,45,46]$. Some amount of paramagnetic contribution from $\pi$-bond graphitic networks might also be present, considering the carbon $s p^{2}$ content of these films (Fig. 8) [43]. However, if present, the crystalline graphitic content must be very small due to the fact that EPR spectra of a-C:H:Si:O do not show any asymmetry or large distributions in $g$-values, which are characteristic of graphitic EPR powder patterns [44, 59].

The integrated EPR signal intensity ( $2^{\text {nd }}$ integral of the derivative lineshape) is proportional to the number of detected unpaired spins. Therefore the sample spin density $\left(N_{s}\right.$, in units $\mu_{e} / \mathrm{g}$, where $\mu_{e}$ signifies unpaired electron magnetic moments) can be obtained by comparing the integral with that of a standard sample containing a known number of spins (TEMPO calibration, see Experimental Section). This analysis shows that the spin number density $N_{s}$ in a-C:H:Si:O progressively decreases upon annealing (Fig. 2). For comparison, the $N_{s}$ data compiled by Barklie for carbon films fabricated by a variety of methods [42] show a relatively constant $N_{s}$ for annealing 
temperatures between $20^{\circ} \mathrm{C}$ and $300^{\circ} \mathrm{C}$. On the other hand, the temperature dependence of $N_{s}$ data presented in Fig. 2 appears to be closer to that of hydrogenated tetrahedral amorphous carbon (ta$\mathrm{C}: \mathrm{H})$ materials prepared by Conway et. al. $[60,61]$. A possible mechanism for the decrease in $N_{s}$ in a-C materials upon annealing is the reduction of internal stresses and decrease in hydrogen content. These processes involve the scission of $\mathrm{C}-\mathrm{H}$ bonds and passivation of defects, which results in an increased $s p^{2}$ content. However, this description does not completely account for the data presented here, which were gathered at lower annealing temperatures. Although a defect passivation mechanism (i.e., coalescence of carbon defects, atomic hydrogen recombination and/or capture at carbon defect sites) is likely responsible for the $N_{s}$ behavior, the required mechanism must not rely significantly on covalent bond breaking, carbon rehybridization and carbon $s p^{2}$ clustering for the following reasons: 1) the EPR signal is not consistent with a graphitic interpretation (although the carbon $s p^{2}$ content increases slightly upon annealing at $200-300^{\circ} \mathrm{C}$ ); 2) while $N_{s}$ continues to decrease, the hydrogen content $\left(N_{H}\right)$ decreases to a lower extent with increasing annealing temperature (Fig. 4).

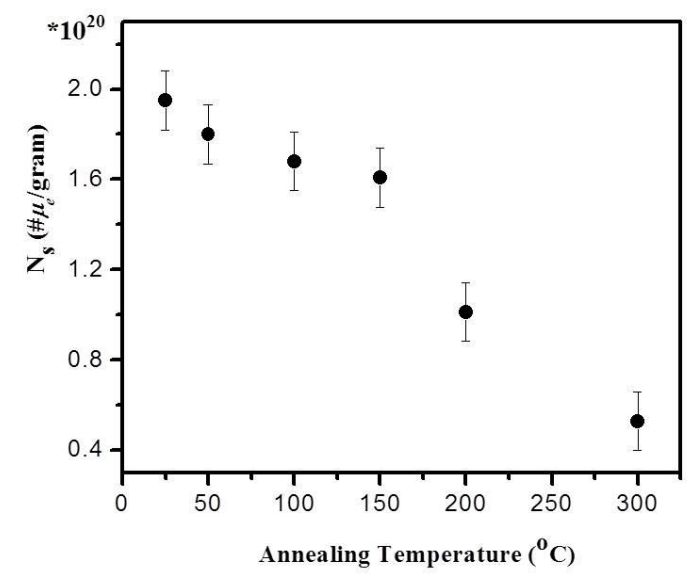

Figure 2. $N_{s}$ (unpaired spin density) in units of \# unpaired electron magnetic moments $\left(\mu_{\mathrm{e}}\right)$ per g of aC:H:Si:O w.r.t. annealing temperature. The data in this figure have an uncertainty of about $\pm 7 \%$.

\section{$3.2{ }^{1} H N M R$}

Investigating the correlation between carbon hybridization, hydrogen content, structural defects, topological disorder (i.e., clustering of $s p^{2}$ carbons) and macroscopic behavior is of primary importance in characterizing a-C:H films [62]. Along these lines ${ }^{1} \mathrm{H}$ NMR was employed to probe magnetic environments and motional dynamics for hydrogen in the material.

Room temperature static and MAS ${ }^{1} \mathrm{H}$ spectra of the unannealed a-C:H:Si:O is displayed in Fig. 3. The static lineshape reflects a large structural distribution of hydrogen sites containing both 
relatively narrow and broad components. The MAS lineshape displays a single isotropic peak ( 0 ppm) flanked symmetrically by sidebands. Even though the proton chemical shift range is not large enough to provide resolution of specific hydrogen sites $\left(\mathrm{CH}, \mathrm{CH}_{2}\right.$ and $\left.\mathrm{CH}_{3}\right)$ even under MAS, dynamic information and absolute content can be obtained from these spectra.

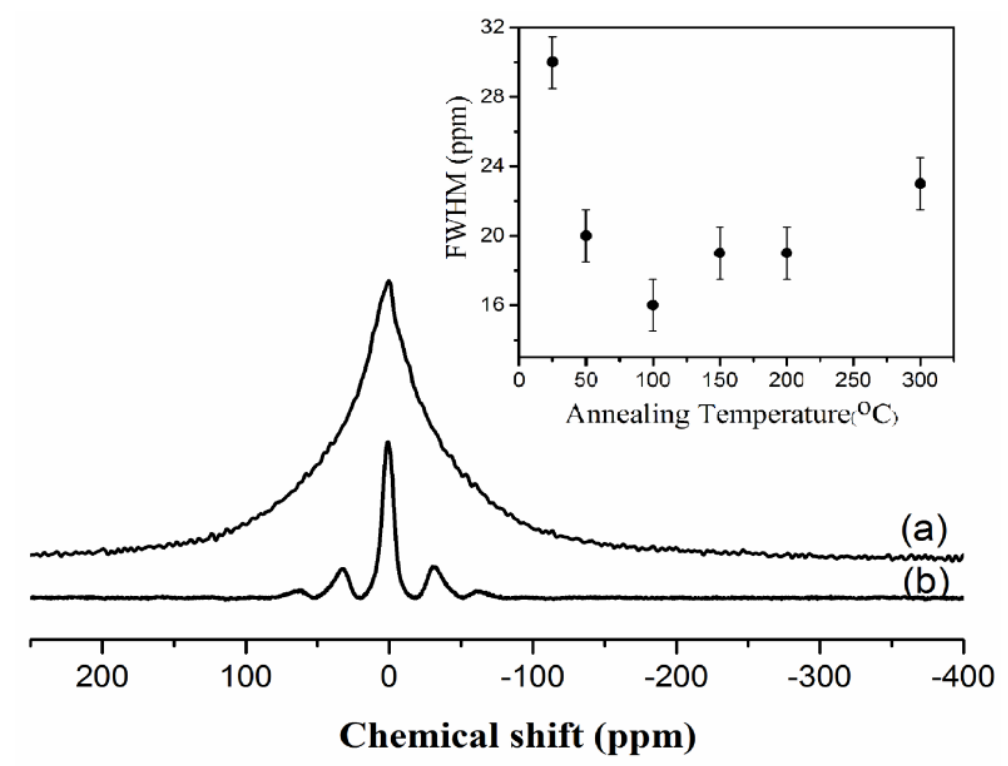

Figure 3. (a) Static and (b) MAS ${ }^{1} \mathbf{H}$ NMR echo spectrum with $\tau=35 \mu$ s for the as-prepared a$\mathrm{C}: \mathrm{H}: \mathrm{Si}: \mathrm{O}$ sample; the insert is the resonance linewidth w.r.t. annealing temperature for the static case. The linewidth data has an uncertainty of about $\pm 5 \%$.

After an initial dramatic decrease of about $1 / 2$ in full-width at half maximum (FWHM) upon annealing beyond $50^{\circ} \mathrm{C}$, the general lineshape for the most part decreases in intensity w.r.t. annealing temperature, whereas linewidths appear to increase only slightly upon annealing between $50^{\circ} \mathrm{C}$ and $300^{\circ} \mathrm{C}$. Low temperature spectra (at $-50^{\circ} \mathrm{C}$, not shown) of the unannealed sample are roughly twice as broad, and therefore indicate the presence of mobile hydrogen-containing species at room temperature. The results indicate that initial annealing at $50^{\circ} \mathrm{C}$ gives substantial molecular effusion, in the form of ambient water, and/or simple hydrocarbons. Effusion of molecular hydrogen (and perhaps other hydrocarbons) is known to occur more prominently with annealing at much higher temperatures due to the recombination of atomic hydrogen by thermally-activated structural changes $[60,61]$.

The observation of two very different time scales in the spin-echo results of Figure 4 leads to the bi-exponential proton relaxation formulation of Eqn. 1. It is from this analysis by which both characteristic spin-spin relaxation times $T_{2}^{\prime}, T_{2}^{\prime \prime}$ (short and long resp.) and the weightings $f$ are determined (Table I). 


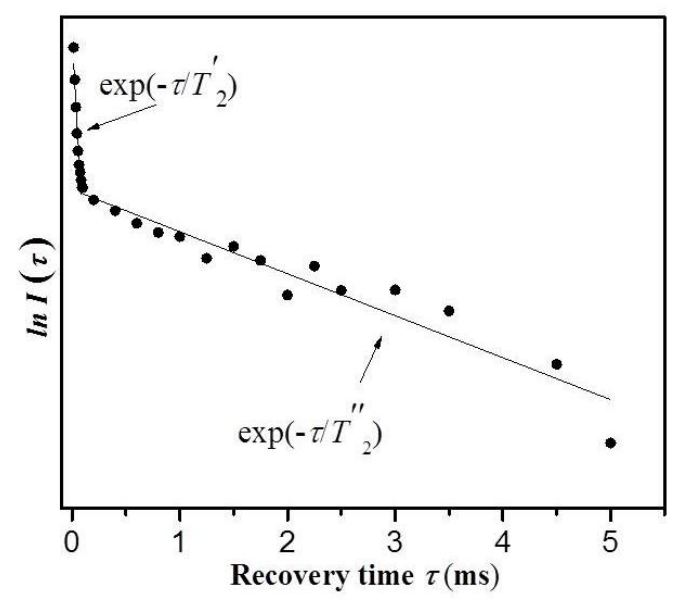

Figure 4. Hydrogen heterogeneity is evident by the two recovery components in the ${ }^{1} \mathrm{H}$ NMR echo intensity (logarithm) vs. $\tau$ (dephasing time) for the as-prepared a-C:H:Si:O sample. The two asymptotic rates, $1 / T_{2}$ ' and $1 / T_{2}$ ', are clearly apparent in the bi-exponential linear regression analysis as exhibited by the solid line curve. The $T_{2}$ values and weightings are presented in Table 1 and used for Fig. 5.

Table 1. $T_{1}(\mathrm{C}), T_{2}(\mathrm{C}), T_{1}(\mathrm{H})$, and $T_{2}(\mathrm{H})$ of annealed a-C:H:Si:O*

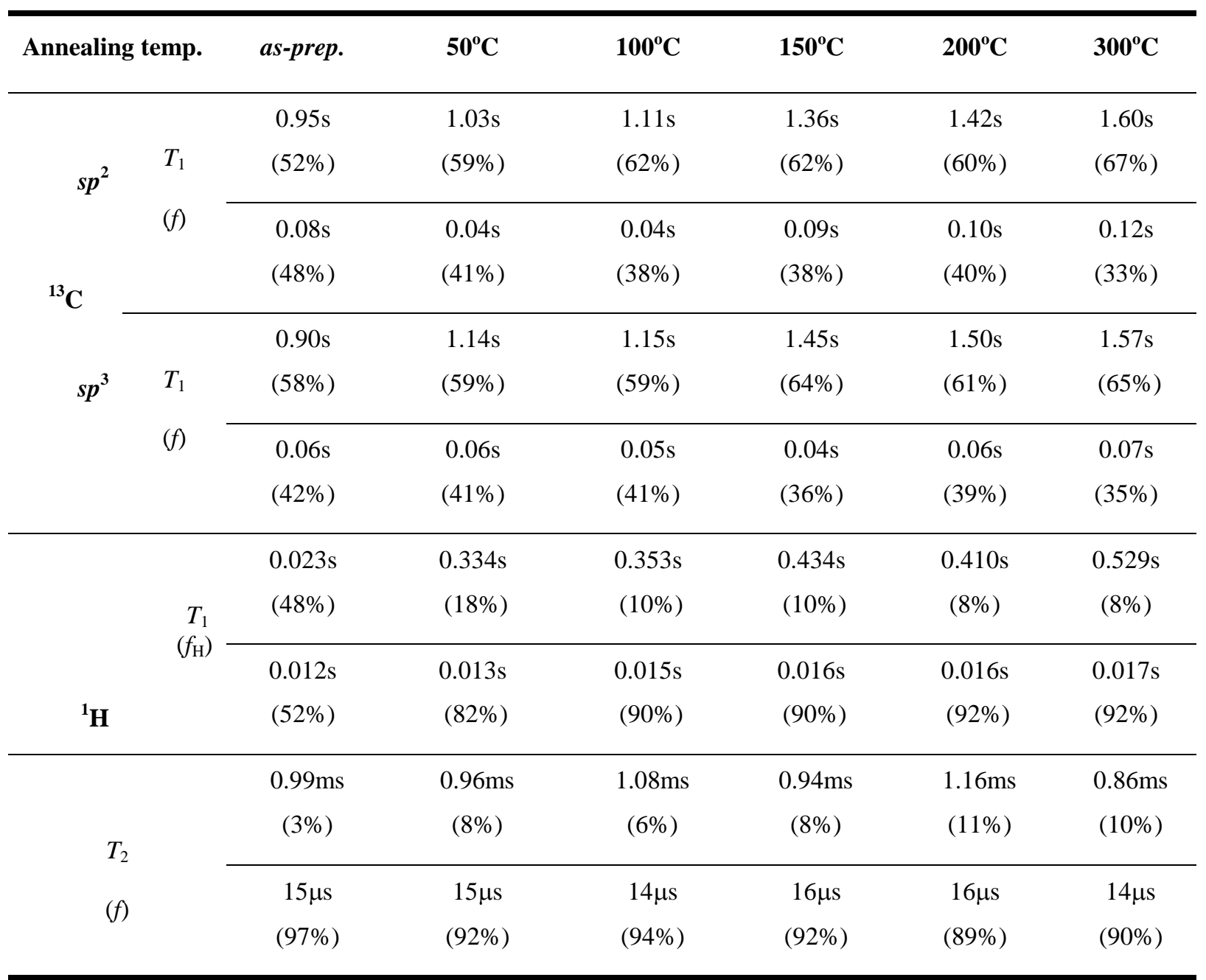

*Results of bi-exponential expressions, Eqns. 1 and 2. 
The majority of protons $(\geq 90 \%)$ are characterized by very short spin-spin relaxation times near $15 \mu \mathrm{s}$, whereas the remaining $10 \%$ or less have $T_{2} \sim 1 \mathrm{~ms}$. There are some interesting trends in the data. For instance, the fraction of short- $T_{2}$ protons decreases slightly upon annealing (unlike the $T_{1}$ data). This proton population experiences strong interactions with neighboring paramagnetic dangling-bond defects, yet their fraction will decrease as the paramagnetic content becomes less concentrated with annealing ( $N_{s}$ data of Fig. 2). There is hydrogen loss as well, and this can be monitored through $N_{H}$, which is obtained according to the procedure outlined above from extrapolated $I(0)$ values via Eqn. 1. The results for $N_{\mathrm{H}}$ are plotted in Fig. 5 at each annealing temperature.

$$
I(\tau)=I(0)\left[f e^{-\frac{\tau}{T_{2}^{\prime}}}+(1-f) e^{-\frac{\tau}{T_{2}^{\prime \prime}}}\right]
$$

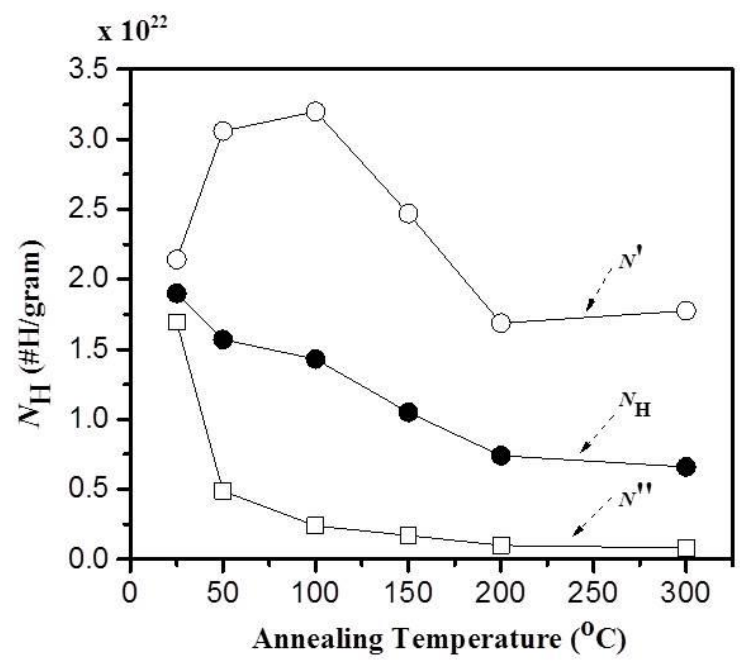

Figure 5. Total hydrogen concentration ( $N_{H}$ as measured via NMR) of a-C:H:Si:O samples w.r.t. annealing temperature (filled circles, $\bullet$ ). $N_{H}$ is determined from the intercept of spin-echo data, via Eqn. 1). The data in this figure have an error of about $\pm 10 \%$ and the lines are guides for comparison. $N$ ' and $N$ ' are the hydrogen concentrations derived respectively for the $\left(s p^{2}-s p^{3}\right)_{T, 1}$ and $\left(s p^{2}-s p^{3}\right)_{T}{ }^{\prime \prime}$ carbon-silica groups (see discussion).

Additional insight can be gained through spin-lattice relaxation measurements $\left(T_{1}\right)$. Previous $T_{1}$ analyses of a-C:H materials have used bi-exponential recovery profiles to evaluate proton magnetic relaxation $[32,41]$. For this analysis of saturation recovery data, a bi-exponential formulation is used as well (Eqn. 2), where characteristic relaxation times $T_{1}^{\prime}, T_{1}^{\prime \prime}{ }_{1}$ (short and long resp.) and the weightings $f$ are determined accordingly (Fig. 6, top).

$$
I(\tau)=I(\infty)\left[f\left(1-e^{-\frac{\tau}{T_{1}^{\prime}}}\right)+(1-f)\left(1-e^{-\frac{\tau}{T^{\prime \prime}}}\right)\right]
$$


The reliance upon a bi-exponential magnetic relaxation recovery is not unique, as this approach has been consistently used in many magnetic resonance relaxation studies of sputtered and CVD a-C:H materials. Stretched-exponential schemes have been applied as well, although the formalism of its direct application to magnetization data is less grounded. It has been used nevertheless to account for the effect on relaxation due to very broad and heterogeneous distributions of paramagnetic spins $[41,63]$.

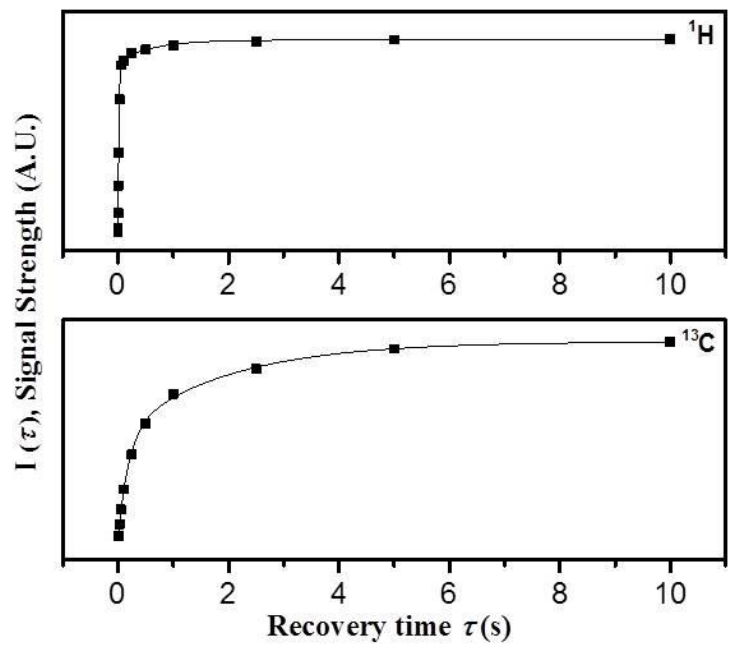

Figure 6. ${ }^{1} \mathrm{H}$ (top) and ${ }^{13} \mathrm{C}$ (bottom) spin-lattice relaxation $\left(T_{1}\right)$ profiles (signal strength, $I(\tau)$ vs. $\tau$ ) expressed in arbitrary units, for the $150^{\circ} \mathrm{C}$ annealed a-C:H:Si:O sample. The solid curve is the biexponential "best-fit" obtained using Eqn. 2.

The fitting results given in Table I reveal that a large fraction of protons are characterized by short $T_{1}$ values $(\sim 10 \mathrm{~ms})$. An apparent difference with the $T_{2}$ behavior is that the short- $T_{1}$ proton fraction increases with the sample annealing temperature. This is perhaps better understood considering the decreasing long- $T_{1}$ fraction, i.e., the result when more mobile long- $T_{1}$ protons leave due to effusion, defect passivation and consolidation of hydrogen-free domains. The presence of surface adsorbed molecular entities (e.g., water) will tend to enhance the long- $T_{1}$ fraction; therefore, as these volatile species leave the material at $50^{\circ} \mathrm{C}-100^{\circ} \mathrm{C}$, the less volatile short- $T_{1}$ proton fraction increases. The as-prepared a-C:H:Si:O has a hydrogen concentration of about $1.9 \times 10^{22} \mathrm{~g}^{-1}$; however, as the data reveal (considering the difference between the first values, $\Delta N_{H} \sim 0.3 \times 10^{22} \mathrm{~g}^{-}$ ${ }^{1}$ ), a significant portion of $N_{H}$ is due to the ambient water content. In other words, the change of the hydrogen content for temperatures less than about $100^{\circ} \mathrm{C}$ is largely associated with the desorption of water and other surface hydrogen-containing species. Also, due to hydrogen effusion there is a steady reduction of $N_{\mathrm{H}}$ through anneals up to $200^{\circ} \mathrm{C}$, after which the concentration appears to level off near $0.7 \times 10^{22} \mathrm{~g}^{-1}$. These data are averaged over both short and long- $T_{1}$ populations, yet the 
proposed structure (see discussion below) allows for a separated analysis of these components, as $N_{H}$ can be decomposed into proton populations associated with $T_{1}^{\prime}$ and $T_{1}^{\prime \prime}$, given as $N^{\prime}$ and $N^{\prime \prime}$ in Fig. 5. We next discuss the ${ }^{13} \mathrm{C}$ relaxation and it will be seen that there are also two populations with distinct relaxation behavior. However it is important not to impute a simple one-to-one relationship between the ${ }^{1} \mathrm{H}$ and ${ }^{13} \mathrm{C}$ results because unlike for protons discussed above, there are no volatile effusing carbon species with increasing annealing temperature.

\section{$3.3{ }^{13} \mathrm{CNMR}$}

The ${ }^{13} \mathrm{C}$ MAS NMR spectrum in Fig.7 for the as-prepared a-C:H:Si:O reveals solid-state chemical shift anisotropy/distributions and magnetic dipolar interactions between ${ }^{13} \mathrm{C}$ and surrounding spins. These dominant interactions account for the peak positions and side band patterns observed. Unlike some previous ${ }^{13} \mathrm{C}$ results published in the literature, no significant variations in the spectra were observed using proton decoupling, although cross-polarization was observed. It is assumed that higher power decoupling can improve overall signal strength for hydrogen-containing amorphous carbon materials. Nevertheless, all data in this study were obtained without proton decoupling. The well-established ${ }^{13} \mathrm{C}$ chemical shifts for carbon hybridizations in a$\mathrm{C}$ materials assign the peak at $140 \mathrm{ppm}$ to $s p^{2}$ carbons and the more shielded peak at $56 \mathrm{ppm}$ to $s p^{3}$ carbons. No variation of peak position was observed due to annealing. Integration of these spectral signatures gives the fractions of carbons in $s p^{2}$ and $s p^{3}$ environments, as shown in Table II and Fig. 8 left. The results indicate that the $s p^{2}$ content starts at about $65 \%$ for the as-prepared material and slightly increases to just over $70 \%$ for the $300^{\circ} \mathrm{C}$ annealed sample. 


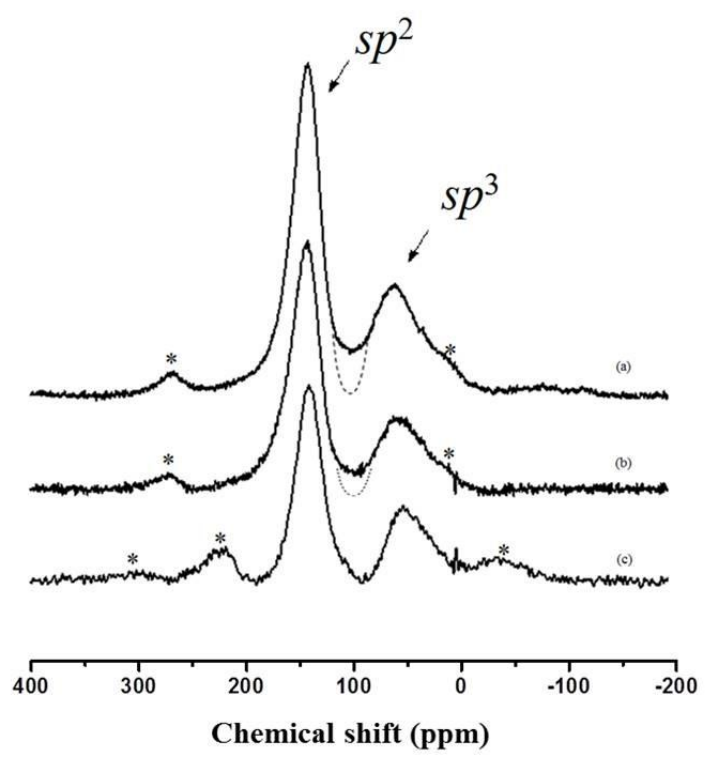

Figure 7. ${ }^{13} \mathrm{C}$ MAS NMR spectra (scale relative to TMS) of the as-prepared (unannealed) a-C:H:Si:O sample. Top spectrum (a) is the spin-echo ( $\tau=35 \mu \mathrm{s})$, middle spectrum (b) single-pulse (DP), and bottom spectrum (c) obtained using CP. Note the varied signal strengths within the dotted curve (see text). *denotes spinning sidebands.

Comparison of the spectra collected via spin-echo, direct polarization (DP) and ${ }^{1} \mathrm{H}-{ }^{13} \mathrm{C} \mathrm{CP}$ measurements (also shown in Fig. 7) indicates the presence/absence of certain spectral features within the region bordered by the $s p^{2}$ and $s p^{3}$ peaks $(\sim 100 \mathrm{ppm})$. Among the three methods, the echo provides the most accurate estimation of the $s p^{2}$ and $s p^{3}$ resonance intensities. However, it is noted that significant paramagnetic density is encountered for this sample $\left(\sim 10^{20} \mu_{e} / g\right)$ and undoubtedly some of the ${ }^{13} \mathrm{C}$ NMR signal is rendered unobservable due to extremely short transverse magnetic relaxation, regardless of $\mathrm{DP}, \mathrm{CP}$ or echo. This issue will be revisited below in light of the experimental results. The more attenuated signal intensity around $100 \mathrm{ppm}$ observed in the DP spectrum suggests a very short spin-spin interaction for associated carbons (e.g., carbon $T_{2} \leq$ $15 \mu \mathrm{s}$, within the instrument deadtime after the pulse). In the CP spectrum, the almost complete absence of ${ }^{13} \mathrm{C}$ signal in this region indicates zero correlation between the associated carbons and their closest protons. This ${ }^{13} \mathrm{C}$ signal is largely composed of unprotonated and highly disordered $s p^{2}$ carbons characterized by very short $T_{2} \mathrm{~s}$. A consistent assignment for this spectral component, made by $\mathrm{Xu}$ et al. near $105 \mathrm{ppm}$, is for disordered non-graphitic $s p^{2}$ carbons [41]. 
Table 2. Fraction of carbon atoms in $\mathrm{sp}^{2}$ and $\mathrm{sp}^{3}$ hybridization state together with the unpaired spin density $\left(N_{s}\right)$ and the number of hydrogen atoms $\left(N_{H}\right)$. Additionally, the computed $z$ values (for the formula $\left.\left(\mathrm{SiO}_{x}\right)_{y}-\mathrm{CH}_{z}\right)$ and the number of unpaired electron spins per carbon $\left(\mu_{e} /[\mathrm{C}]\right)$ are reported.

\begin{tabular}{ccccccc}
\hline $\begin{array}{c}\text { annealing } \\
\text { temp. }\end{array}$ & $f_{s p 2}$ & $f_{s p 2} / f_{s p 3}(*)$ & $N_{S} \times \mathbf{1 0}^{\mathbf{2 0}} \mathbf{g}^{-1}$ & $N_{\mathbf{H}} \times \mathbf{1 0}^{\mathbf{2 2}} \mathbf{g}^{-1}$ & $z$ & $\begin{array}{c}\boldsymbol{\mu}_{e} /[\mathbf{C}] \\
\times \mathbf{1 0}^{-3}\end{array}$ \\
\hline as-prepared & $0.658 \pm 0.050$ & 1.92 & $1.95 \pm 0.13$ & $1.90 \pm 0.19$ & $0.52 \pm 0.04$ & 5.3 \\
\hline $50^{\circ} \mathrm{C}$ & 0.662 & 1.99 & 1.80 & 1.57 & 0.43 & 4.9 \\
\hline $100^{\circ} \mathrm{C}$ & 0.665 & 2.01 & 1.68 & 1.43 & 0.39 & 4.6 \\
\hline $150^{\circ} \mathrm{C}$ & 0.667 & 2.00 & 1.61 & 1.05 & 0.28 & 4.4 \\
\hline $200^{\circ} \mathrm{C}$ & 0.685 & 2.17 & 1.01 & 0.74 & 0.20 & 2.7 \\
\hline $300^{\circ} \mathrm{C}$ & 0.727 & 2.66 & 0.53 & 0.66 & 0.18 & 1.4 \\
\hline$f_{s p 3}=1-f_{s p 2}$ & & & & & &
\end{tabular}

The ability of resolving $s p^{2}$ and $s p^{3}$ carbons in ${ }^{13} \mathrm{C}$ MAS spectra allows for independent $T_{1}$ measurements, which thereby can provide further insights into the carbon environments. The results of a bi-exponential analysis (Eqn. 2) on the saturation-recovery data (e.g., bottom of Fig. 6), as compiled in Table I, show that the ${ }^{13} \mathrm{C}$ spin-lattice relaxation does not discriminate unequivocally between $s p^{2}$ and $s p^{3}$ carbons. As the overall fraction of carbons characterized by $T^{\prime}{ }_{1}(\sim 40-120 \mathrm{~ms})$ decreases somewhat from the as-prepared value, $T{ }^{\prime \prime}{ }_{1}$ for the remaining majority of carbons $(\sim 60 \%)$ increases slightly. This is not surprising, since the ${ }^{13} \mathrm{C}$ relaxation is enhanced by dangling-bond paramagnetic defects whose concentration $\left(N_{s}\right)$ also decreases with annealing. Although there is no discernable contrast in the relaxation between $s p^{2}$ and $s p^{3}$ carbons, a different association can be made between separate carbon groups, due to the very different relaxation characteristics that they exhibit. In this way, the data allows for the identification of two carbon groups characterized by

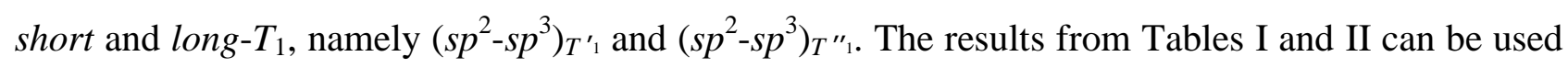
to monitor the fractions of carbon in these groups w.r.t. annealing (labeled $f^{\prime}$ and $f^{\prime \prime}$ respectively), as compiled in Table 3.

Table 3. Fraction of carbon atoms with long and short $\mathbf{T}_{1}$

\begin{tabular}{|c|c|c|c|c|c|c|c|c|c|}
\hline $\begin{array}{c}\text { Annealing } \\
\text { temp. }\end{array}$ & $f_{s p 2}^{\prime}$ & $f_{s p 3}^{\prime}$ & $f_{s p 2}^{\prime \prime}$ & $f_{s p 3}^{\prime \prime}$ & $f_{s p 2}^{\prime} / f_{s p 3}^{\prime}$ & $f^{\prime \prime}{ }_{s p 2} / f^{\prime \prime}{ }_{s p 3}$ & $\begin{array}{l}f^{\prime}\left(s p^{2}-\right. \\
\left.s p^{3}\right)_{T T^{\prime}}\end{array}$ & $z^{\prime}$ & $z^{\prime \prime}$ \\
\hline as-prep. & 0.316 & 0.144 & 0.342 & 0.198 & 2.2 & 1.7 & 0.46 & 0.59 & 0.46 \\
\hline $50^{\circ} \mathrm{C}$ & 0.271 & 0.139 & 0.391 & 0.199 & 2.0 & 2.0 & 0.41 & 0.86 & 0.13 \\
\hline $100^{\circ} \mathrm{C}$ & 0.253 & 0.137 & 0.412 & 0.198 & 1.8 & 2.1 & 0.39 & 0.90 & 0.06 \\
\hline $150^{\circ} \mathrm{C}$ & 0.253 & 0.120 & 0.414 & 0.213 & 2.1 & 1.9 & 0.37 & 0.68 & 0.05 \\
\hline $200^{\circ} \mathrm{C}$ & 0.274 & 0.123 & 0.411 & 0.192 & 2.2 & 2.1 & 0.40 & 0.46 & 0.03 \\
\hline $300^{\circ} \mathrm{C}$ & 0.240 & 0.096 & 0.487 & 0.177 & 2.5 & 2.7 & 0.34 & 0.49 & 0.02 \\
\hline
\end{tabular}

Fig. 8 (right) shows through the ratio, $f^{\prime \prime} / f^{\prime}$, how annealing enhances the $\left(s p^{2}-s p^{3}\right)_{T}{ }^{\prime \prime}$ content at the expense of the $\left(s p^{2}-s p^{3}\right)_{T}{ }_{1}$ content. Some insight into the internal make-up of these carbon 
networks may be obtained by considering the effect of annealing on their respective $f_{s p 2} / f_{s p 3}$ ratios. As shown in Fig. 9, there appears to be slight enhancement in the $s p^{2}$ content at the $300^{\circ} \mathrm{C}$ annealing temperature in $f^{\prime \prime}$ relative to $f^{\prime}$. These data reveal an important aspect of the structural evolution within the material, and will be discussed below.
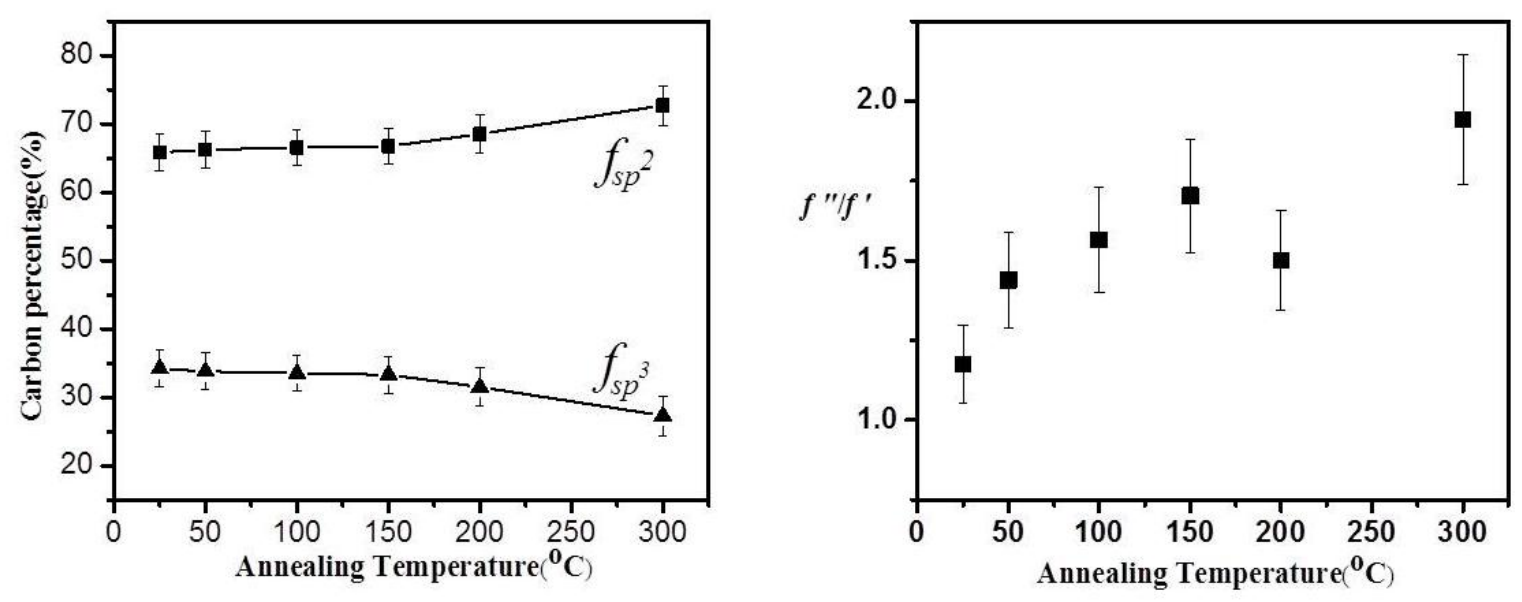

Figure 8. Left: The fractional components of carbon hybridized as $s p^{2}$ and $s p^{3}$ in a-C:H:Si:O samples w.r.t. annealing temperature. The lines are guides for comparison and the error bars represent an uncertainty of about $\pm 4 \%$. Right: The ratio of carbon groups characterized by short $\left(f^{\prime}=f_{s p 2}{ }^{\prime}+f_{s p 3}\right.$ ') and long $\left(f,=f_{s p 2} "+f_{s p 3},\right)$ spin-lattice relaxation times (uncertainty of about $\pm 6 \%$ ).

The issue regarding the effect on the NMR by large paramagnetic concentrations, i.e., the $s p^{2} / s p^{3}$ evaluation, refers to signal wipeout which is typically encountered in paramagnetic systems, as electron-nuclear dipolar couplings can shorten $T_{2}$ to less than a few $\mu$ s. Since the NMR signal decays at a rate proportional to $1 / T_{2}$, significant spectral information can be lost within the instrument deadtime, which is in the best of circumstances typically on the order of $10 \mu$ s or so. The problem could be exacerbated in the present case, as previously reported ${ }^{1} \mathrm{H}$ and ${ }^{13} \mathrm{C} T_{1}$ values [32, 41] are generally longer than those reported here for a-C:H:Si:O films. This is believed to be an effect of larger dangling bond paramagnetic content in the a-C:H:Si:O material. Concerning the proton counts, via spin-echo results analyzed with Eqn. 1, it is assumed that the linear extrapolation to the intercept, $I(0)$, gives a reasonably accurate measure of the proton magnetic moments, including the undetected ${ }^{1} \mathrm{H}$ short- $T_{2}$ components. On the other hand, the breakdown of protons into weightings according to Eqn. 2 is less reliable, since the saturation method becomes more difficult to implement for $T_{1}<1 \times 10^{-4} \mathrm{~s}$. Nevertheless, an important outcome from the ${ }^{1} \mathrm{H} T_{1}$ analyses is that upon annealing, an increasingly large fraction of protons (up to over $90 \%$ at the higher annealing temperatures) are characterized by a fast-relaxation mechanism. ${ }^{13} \mathrm{C}$ NMR signal intensities can also be adversely affected by large paramagnetic interactions [64]. For instance, Cho et al.[32] have reported signal losses of about $50 \%$ due to high paramagnetic content for a variety of sputtered a- 
$\mathrm{C}: \mathrm{H}$ samples. It is therefore likely that not all ${ }^{13} \mathrm{C}$ nuclei are represented in the a-C:H:Si:O spectra. As stated, the interpretation given here envisions the carbon group in terms of distinct relaxation subdivisions of similar $f_{s p 2} / f_{s p 3}$ ratios (i.e. $f_{s p 2} / f_{s p 3} \approx f^{\prime}{ }_{s p 2} / f^{\prime}{ }_{s p 3} \approx f^{\prime \prime}{ }_{s p 2} / f^{\prime \prime}{ }_{s p 3}$ ), which includes any undetected $\left(s p^{2}-s p^{3}\right)$ factions with extremely short $T_{2} \mathrm{~s}$. Since the relaxation does not discriminate between $s p^{2}$ and $s p^{3}$ carbons, even within the undetected factions, the quantitative $s p^{2} / s p^{3}$ analysis is not significantly affected by paramagnetic wipeout effects.

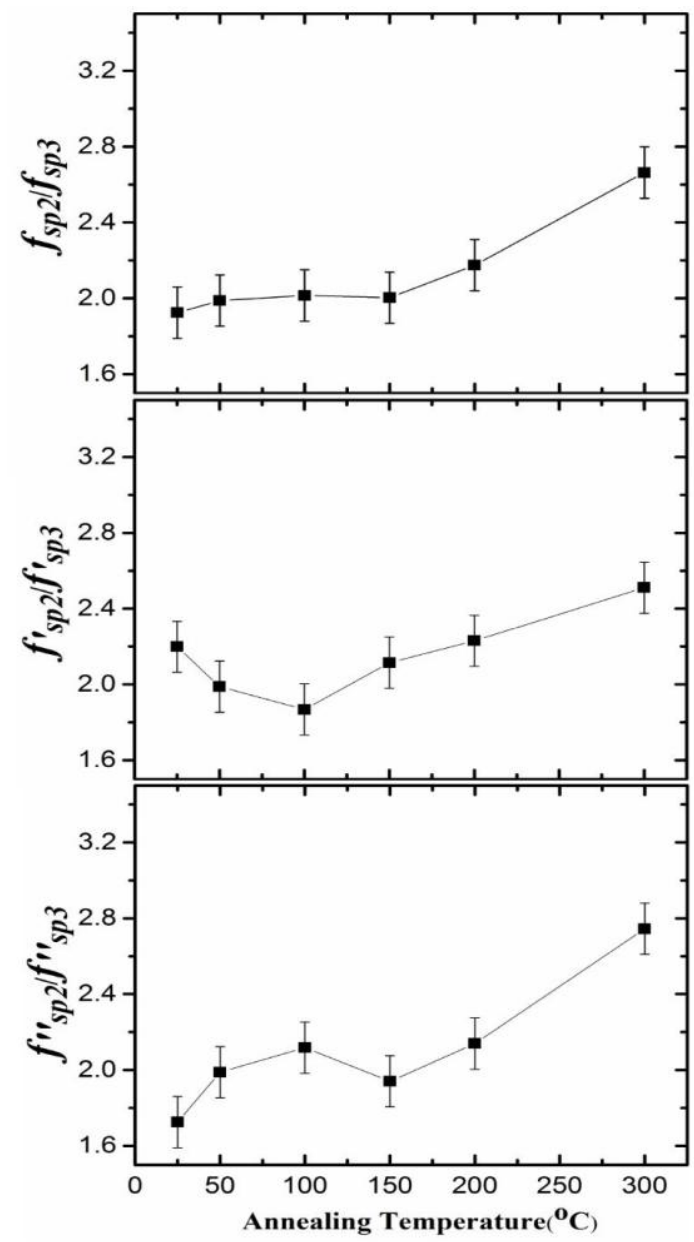

Figure 9. Ratio of the fraction of all $s p^{2}$ and $s p^{3}$ carbons: $f_{s p 2} / f_{s p 3}$ from integrated ${ }^{13} \mathrm{C}$ spectra (top); $f{ }_{s p 2} / f{ }_{s p 3}$ from short-relaxation time data (center); and $f{ }^{\prime}{ }_{s p 2} 2 f\left({ }^{\prime}{ }_{s p 3}\right.$ from long-relaxation time data (bottom). The center and bottom plots are generated using the ${ }^{13} \mathrm{C} T_{1}$ weightings $(f)$ from table 1 and carbon hybridization weightings $\left(f_{s p 2}\right.$ and $\left.f_{s p 3}\right)$ from Table 2 , i.e., $f{ }_{s p 2}=f \times f_{s p 2}$. The lines are guides for comparison.

Magnetic dipolar interactions between nearby protons and ${ }^{13} \mathrm{C}$ nuclei in $s p^{2}$ and $s p^{3}$ hybridizations can be probed individually by CP-MAS. Since the efficiency of the polarization transfer depends on the strength of the H-C coupling, the contact time can be varied to optimize the signal intensity [65]. Select CP-MAS experiments were performed on the as-prepared and $50^{\circ} \mathrm{C}$ annealed a-C:H:Si:O samples using a variety of contact times between $0.5 \mathrm{~ms}$ and $6.0 \mathrm{~ms}$. The results displayed in Fig. 10 show that the signal strength of $s p^{2}$ carbons is maximized near $2 \mathrm{~ms}$, 
whereas $s p^{3}$ carbons appear to have a maximum below $1 \mathrm{~ms}$. In that the magnetic dipolar relaxation rate during $\mathrm{CP}$ varies inversely with the ${ }^{1} \mathrm{H}_{-}{ }^{13} \mathrm{C}$ distance to the sixth power $[66,67]$, it is generally understood that the $\mathrm{CP}$ effect is more efficient at short dipolar interaction distances, i.e., for immobile protons within a van der Waals contact distance and for direct $\mathrm{C}-\mathrm{H}$ bonds. In order to optimize CP for longer interaction distances (a few $\AA$ ), for suitably long rotating frame relaxation times, the power and/or Hartmann-Hahn match duration (contact time) is usually adjusted gradually to larger values. In this way, an evaluation of the $\mathrm{CP}$ optimization profile can provide a qualitative assessment of the relative ${ }^{13} \mathrm{C}-{ }^{1} \mathrm{H}$ distances for $s p^{2}$ and $s p^{3}$ carbons [68]. The results shown in Fig. 9 indicate that the observed $s p^{3}$ carbons with contact times less than $1 \mathrm{~ms}$, can be characterized as having immobilized hydrogen atoms as close as a single bond length away, whereas $s p^{2}$ carbons with contact times greater than $2 \mathrm{~ms}$ may be better described as having neighboring hydrogen atoms further away, at distances of a few Á (two or three bond lengths). The greater affinity for hydrogen to be associated with $s p^{3}$ over $s p^{2}$ carbons can be partially addressed using purely statistical reasoning [69]; however, a full description requires consideration of nano-clustering and heterogeneous structural distributions. Unfortunately, CP doesn't seem to provide much contrast specifically regarding the $f^{\prime}$ and $f^{\prime \prime}$ content. Overall, these results are consistent with CP-MAS studies of a-C:H [27, 32, 41] and Si-amorphous carbon [35] materials.

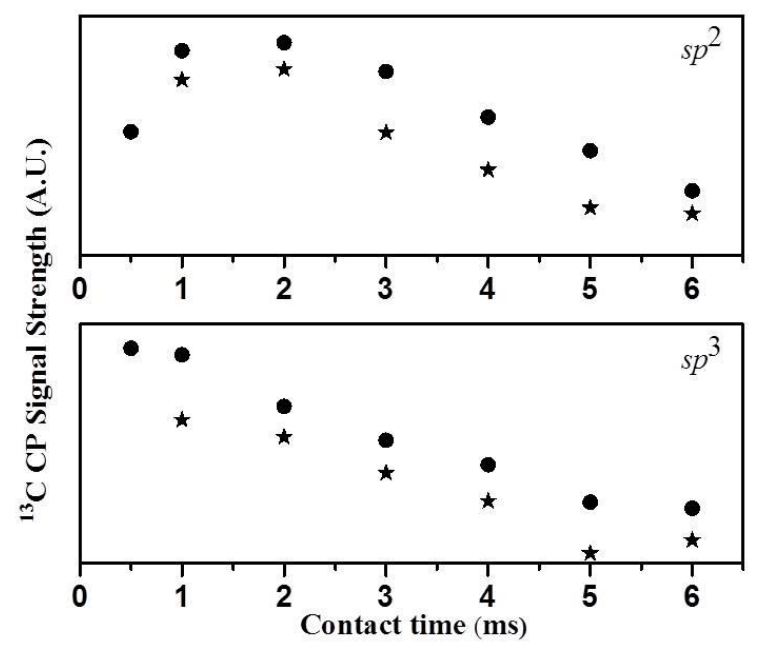

Figure 10. Normalized $s p^{2}$ and $s p^{3}{ }^{13} \mathrm{C}$ peak intensities for the as-prepared material $(\bullet)$ and the $50^{\circ} \mathrm{C}$ annealed sample $(\star)$ as determined using the CP-MAS experiments as a function of the contact time.

\section{$3.4{ }^{29} \mathrm{Si} N \mathrm{NMR}$}

Several conclusions about silicon sites can be inferred from the results. The analysis of ${ }^{13} \mathrm{C}$ NMR results in PECVD grown a-C:H:Si films by Iseki et al. [35] shows that the resonance becomes more shielded with Si content, although those materials contain no oxygen. According to that trend, 
the ${ }^{13} \mathrm{C}$ peak positions reported here at $140 \mathrm{ppm}$ and $56 \mathrm{ppm}$ for respectively $s p^{2}$ and $s p^{3}$ carbon, imply a low $\mathrm{Si}$ content for the a-C:H:Si:O material under investigation. This is in agreement with the outcomes of the chemical analysis of the as-deposited materials by Rutherford backscattering spectrometry (RBS). Based on the observed ${ }^{29} \mathrm{Si}$ chemical shift (-11 ppm, Fig. 11), the silicon site appears to be covalently situated within the carbon $\left(s p^{2}-s p^{3}\right)$ group; quite possibly maintaining at least 3 carbon neighbors [35], and at most one hydrogen. For comparison, SiC is known to give shifts within the range of -14 to -25 ppm depending on the crystal environment about silicon atoms, and the cubic form gives a resonance near $-18 \mathrm{ppm}$ [70]. The data are not conclusive concerning the presence of $\mathrm{Si}-\mathrm{O}$ bonds, as the resonance of the $\mathrm{SiC}_{3} \mathrm{O}$ unit is expected to be near $-6 \mathrm{ppm}$, and other oxycarbides $\left(\mathrm{SiC}_{2} \mathrm{O}_{2}, \mathrm{SiCO}_{3}, \mathrm{SiO}_{4}\right)$ typically reside beyond $-30 \mathrm{ppm}$ [71]. Since the width of the MAS spectrum is about $90 \mathrm{ppm}$, the existence of some of these units cannot be categorically discounted. There is no strong evidence for the existence of larger silicon groupings, i.e., $\mathrm{SiSi}_{4-n} \mathrm{C}_{n}$, as they generally give more shielded ${ }^{29} \mathrm{Si}$ resonances within $-34 \mathrm{ppm}$ to $-136 \mathrm{ppm}$ [72].

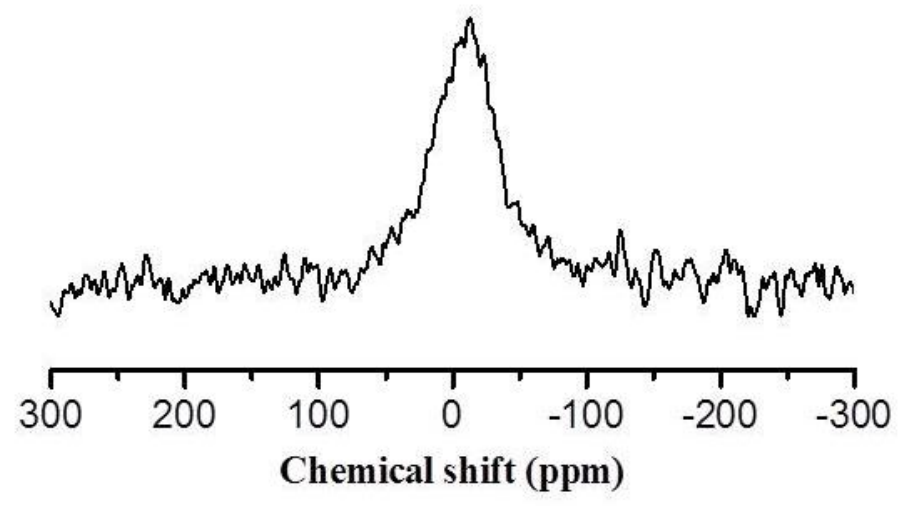

Figure 11. ${ }^{29} \mathrm{Si}$ MAS NMR spectrum for the as-prepared a-C:H:Si:O sample.

Considering the ${ }^{1} \mathrm{H}_{-}^{29} \mathrm{Si} \mathrm{CP}$ results summarized in Fig. 12, an interpretation analogous to that of carbon can be made where the maximizing contact time of about $2.8 \mathrm{~ms}$ indicates that direct $\mathrm{Si}-\mathrm{H}$ bonds are not abundant and of the ${ }^{1} \mathrm{H}$-coupled silicon atoms, most are probably associated with an immobile proton at least two bond lengths away (i.e., hydrogen bound to a neighboring carbon or oxygen atom). 


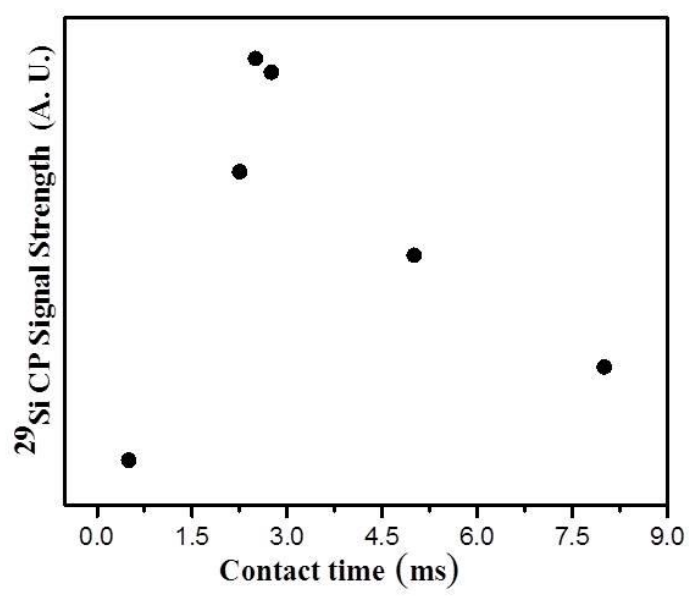

Figure 12. ${ }^{29} \mathrm{Si}$ CP-MAS NMR peak intensity for the as-prepared a-C:H:Si:O sample as a function of the contact time.

\section{Discussion}

The NMR and EPR data presented here is now used to obtain a structural perspective of the PECVD grown a-C:H:Si:O film and how its structure evolves under moderate heating. The average number density of dangling-bonds, hydrogen content and carbon $s p^{2} / s p^{3}$ profile in as-prepared material appears to be typical for amorphous hydrogenated carbon materials; however, certain stand-out features are evident: 1) the heterogeneity in the hydrogen distribution; and/or 2) the dangling-bond distribution; and 3) the absence of graphitic $s p^{2}$ nanoclusters. The interpretation given here is of two silicon- and oxygen-infused $\left(s p^{2}-s p^{3}\right)$ carbon groups with somewhat similar $s p^{2} / s p^{3}$ ratios, i.e., similar carbon composition within experimental uncertainty, yet very different in their respective defect and hydrogen contents. Since the identification is largely based on magnetic relaxation, there is some uncertainty in describing the overall structure this way. For instance, the long-range structure could be viewed as a random arrangement of large segregated silicon oxidecarbon $\left(s p^{2}-s p^{3}\right)$ networks. On the other hand, the picture could be that of a more integrated arrangement of smaller silicon oxide-doped $f^{\prime}$ clusters within a matrix of silicon oxide-doped $f$ " content. This point will be discussed below.

Annealing has the effect of increasing $f_{s p 2}$, and decreasing $f_{s p 3}, N_{S}$ and $N_{H}$. Also, the main dynamical argument, which correlates both ${ }^{1} \mathrm{H}$ and ${ }^{13} \mathrm{C}$ spins with unpaired electron spins, is a normal interpretation of events where relaxation times expectedly tend to get longer as $N_{S}$ decreases. The thermally-induced structural changes within the hydrogen population appear to occur along two fronts: 1) emission of more weakly bound hydrogen-containing species (between 
$20^{\circ}$ and $100^{\circ} \mathrm{C}$ ); and 2) thermally-induced effusion of hydrogen (higher temperatures). Structural interpretation in terms of coexisting carbon groups shows that the $f$ " content increases with annealing, at the expense of the $f^{\prime}$ content. Yet there might be small differences in the $s p^{2} / s p^{3}$ ratios between the two groups, which would indicate differences in the internal structural conversions (i.e., $s p^{3} \rightarrow s p^{2}$ ) occurring with annealing. The structural role of $\mathrm{Si}$ and $\mathrm{O}$ are less clear. In spite of the low $\mathrm{S} / \mathrm{N}$ in the ${ }^{29} \mathrm{Si}$ spectra, the data is consistent with the interpretation of tetrahedral $\mathrm{SiC}_{3} \mathrm{H}$ and $\mathrm{SiC}_{3} \mathrm{O}$ - structural units comprising the bulk of silicon sites in the as-prepared material. It is assumed that these units do not change considerably during annealing up to $300^{\circ} \mathrm{C}$. The discussion below considers the stoichiometry $\left(\mathrm{SiO}_{x}\right)_{y}-\mathrm{CH}_{z}$, the hydrogen content, the defect distributions and how the carbon structure evolves, as monitored through the experimentally determined values for $N_{H}, N_{S}, f_{s p 2}$ and $f_{s p 3}$.

First, the composition parameters $(x, y, z)$ are computed and comparisons are made between the HFS and NMR data. If the ${ }^{29} \mathrm{Si}$ spectrum center-of-gravity at $-11 \mathrm{ppm}$ can be treated as the result of a linear superposition of two structural units, say $\mathrm{SiC}_{3} \mathrm{O}$ at $-6 \mathrm{ppm}$ and $\mathrm{SiC}$ at $-18 \mathrm{ppm}$, then a crude estimation for the number of $\mathrm{O}$ per $\mathrm{Si}$ atoms can be obtained, namely $x=7 / 12 \approx 0.58$. Upon comparison with the RBS values (see experimental section), one obtains $x=[\mathrm{O}] /[\mathrm{Si}]=0.50 \pm 0.19$, and it is clear that the selection of these particular silicon environments is reasonable. As mentioned above, in comparison with the lowest Si content DLC film $([\mathrm{Si}] /[\mathrm{C}]=4 / 66=0.06)$ studied by Iseki et al. [35], the $s p^{2}$ and $s p^{3}{ }^{13} \mathrm{C}$ peak positions for a-C:H:Si:O imply a similarly low value for $y$. Indeed, the RBS values for [Si] and [C] given here show this: $y=0.11 \pm 0.02$. Furthermore, using the HFS value for $[\mathrm{H}]$, one obtains $z=[\mathrm{H}] /[\mathrm{C}]=0.60 \pm 0.02$. Now, using the RBS and HFS values for $x$, $y, z$ and some algebraic analysis,

$$
N_{H}=\frac{z N_{A}}{12.01 \frac{g}{\mathrm{~mol}}+x y\left(16.09 \frac{\mathrm{g}}{\mathrm{mol}}\right)+y\left(28.09 \frac{\mathrm{g}}{\mathrm{mol}}\right)+z\left(1.01 \frac{\mathrm{g}}{\mathrm{mol}}\right)}
$$

where $N_{A}$ is Avogadro's number and the atomic weights of $\mathrm{H}, \mathrm{C}, \mathrm{O}$ and Si have been used, the average hydrogen concentration for the as-prepared material is computed: $N_{H}=2.19 \pm 0.03 \times 10^{22} \mathrm{~g}^{-1}$. In comparison, the NMR value, reflecting about a $10 \%$ uncertainty, is: $N_{H}=1.90 \pm 0.19 \times 10^{22} \mathrm{~g}^{-1}$, which is about $15 \%$ lower than the compositionally determined value. It is highly likely that the discrepancy is more related to the fact that HFS is a strong measure for surface hydrogen down to about $300 \AA$, whereas NMR in principle measures surface and bulk hydrogen. The average number of hydrogen atoms per carbon, determined using $x, y$ and the NMR value for $N_{H}$, is therefore: $z=$ $0.52 \pm 0.04$. These results show in another way how the hydrogen content, being a bit less 
concentrated within the bulk of the film, is heterogeneously distributed throughout the material. The computed $z$ values for the specified annealings are compiled in Table II.

To get a better sense of the defect content, a similar computation can be made for the number of unpaired electron spins per carbon $\left(\mu_{e} /[\mathrm{C}]\right)$ :

$$
\frac{\mu_{e}}{[\mathrm{C}]}=\left[12.01 \frac{\mathrm{g}}{\mathrm{mol}}+x y\left(16.09 \frac{\mathrm{g}}{\mathrm{mol}}\right)+y\left(28.09 \frac{\mathrm{g}}{\mathrm{mol}}\right)\right] \frac{N_{S}}{\left(N_{A}-N_{H}(1.01 \mathrm{~g} / \mathrm{mol})\right)} .
$$

Application of Eqn. 4 to the as-prepared a-C:H:Si:O material, using the RBS values for $x$ and $y, N_{S}=1.95 \pm 0.13 \times 10^{20}$ unpaired spins $/ g$ and $N_{H}=1.90 \pm 0.19 \times 10^{22}$ protons $/ g$, one obtains: $\mu_{e} /[\mathrm{C}]=$ $5.35 \times 10^{-3}$, or about one broken bond defect per 187 carbon atoms. The results for the $300^{\circ} \mathrm{C}$ annealed material yields, $\mu_{e} /[\mathrm{C}]=1.42 \times 10^{-3}$ or about one broken bond defect per 704 carbon atoms on average. Evidently, the defect distribution is heterogeneous as well, since separate relaxation regimes are observed in all ${ }^{1} \mathrm{H}$ and ${ }^{13} \mathrm{C} T_{1}$ and $T_{2}$ measurements. Generally, it is understood that homogeneous magnetic dipole distributions yield classical single-exponential relaxation profiles. Related to this is the evolution of the EPR lineshape from a broader Voigt (60:40 Lorentzian:Gaussian) lineshape towards a purely Lorentzian lineshape upon annealing, where the number of dangling bond defects decreases with annealing temperature. The associated trend in the NMR is the emerging prominence of one component from the bi-exponential at higher annealing temperature (which is more pronounced as the short- $T_{1}$ component in the ${ }^{1} \mathrm{H}$ data, but more subtle in the ${ }^{13} \mathrm{C}$ data as the long- $T_{1}$ component). The simplest interpretation is that of defect annihilation within clusters, leaving behind smaller groups surrounded by large regions of more rarefied defect populations. Extensive low temperature EPR, ${ }^{1} \mathrm{H}$ and ${ }^{13} \mathrm{C}$ NMR relaxation measurements made by Blinc et al. [63] on a-C:H with roughly 35 at.\% hydrogen prepared by CVD provide evidence of paramagnetic clustering. The phenomenon is probably more distinct in their work, since the reported EPR widths are somewhat larger $(6 \mathrm{G})$ while their paramagnetic density is lower $\left(2.5 \times 10^{19}\right.$ $\mu_{e} / \mathrm{g}$ ) than what is reported here for a-C:H:Si:O. The implied picture of a more clustered defect distribution, in the case of the as-prepared material, gives a defect-to-defect distance (within clusters) of less than about 4 or $5 \mathrm{C}-\mathrm{C}$ bond lengths. This distance increases as the defect population lowers such that for the $300^{\circ} \mathrm{C}$ annealed material a defect-to-defect distance of at most 7 or $8 \mathrm{C}-\mathrm{C}$ bond lengths is found.

It is reasonable to link the hydrogen distribution and the silicon oxide-doped carbon groups via the strong paramagnetic interactions that more or less govern relaxations in both. The proposed structure therefore is based on two assumptions: 
1) the short- $T_{1}\left(s p^{2}-s p^{3}\right)_{T^{\prime} 1}$ group $\left(f^{\prime}\right)$ is structurally associated with short- $T_{1}$ hydrogen atoms $\left(f_{\mathrm{H}}\right)$ and a greater density of paramagnetic defects; and likewise the long- $T_{1}\left(s p^{2}-s p^{3}\right)_{T \prime 1}$ group $\left(f^{\prime \prime}\right)$ is structurally associated with long- $T_{1}$ hydrogen atoms and a smaller density of paramagnetic defects;

2) the silicon and oxygen content is homogeneously distributed throughout both $f^{\prime}$ and $f^{\prime \prime}$ and does not change with annealing.

The second assumption is another way of stating that the substantive compositional differences between $f^{\prime}$ and $f^{\prime \prime}$ are solely due to their respective hydrogen and defect contents. This is corroborated by in situ XPS measurements performed under high vacuum conditions (subject of a separate publication), which demonstrated that upon annealing at temperatures above $200^{\circ} \mathrm{C}$ the composition of a-C:H:Si:O changed very slightly (variation of $[\mathrm{C}],[\mathrm{O}]$, and [Si] between $25^{\circ} \mathrm{C}$ and $300^{\circ} \mathrm{C}$ less than 2 at.\%). Furthermore, the similar behavior of their respective $s p^{2} / s p^{3}$ ratios (table III and Fig. 9) shows that their carbon structures are similar. Considering only these, the following relation can be made,

$$
\left(\mathrm{SiO}_{x}\right)_{y}-\mathrm{CH}_{z}=f^{\prime}\left(\mathrm{SiO}_{x}\right)_{y}-\mathrm{CH}_{z^{\prime}}+\left(1-f^{\prime}\right)\left(\mathrm{SiO}_{x}\right)_{y}-\mathrm{CH}_{z}{ }^{\prime \prime}
$$

where $z^{\prime}$ is the number of hydrogen atoms per carbon in the $f^{\prime}$ content, and $z^{\prime \prime}$ is the number of hydrogen atoms per carbon in the $f^{\prime \prime}$ content. But also, the fraction of hydrogen atoms subject to short $T_{1}$ relaxation can be used $\left(f_{\mathrm{H}}\right.$ from Table 1$)$ to separate $z^{\prime}$ from $z^{\prime \prime}$ through the following identifications:

$$
z f_{\mathrm{H}}=f^{\prime} z^{\prime} \quad \text { and } \quad z\left(1-f_{\mathrm{H}}\right)=\left(1-f^{\prime}\right) z^{\prime \prime} \text {, }
$$

or

$$
z^{\prime}=z \frac{f_{H}}{f^{\prime}} \quad \text { and } \quad z^{\prime \prime}=z \frac{\left(1-f_{H}\right)}{\left(1-f^{\prime}\right)}
$$

The number of hydrogen atoms per carbon ( $z$ ), thereby obtained for the two silicon oxide-doped carbon groups are compiled in Table III. These results can in turn be used with Eqn. 3 to obtain the respective concentrations of protons in the two groups, $N^{\prime}$ and $N^{\prime \prime}$, which are plotted with the average hydrogen concentration $N_{\mathrm{H}}$ in Fig. 5 .

This last analysis shows the difference in hydrogen content between the two coexisting silicon oxide-doped carbon groups. As mentioned earlier, the first two sets of data points are 
adversely affected by the additional long- $T_{1}$ fraction $\left(1-f_{H}\right)$ from protons in spectator water molecules, and as a result $N^{\prime}$ and $N^{\prime \prime}$ for the as-prepared and $50^{\circ} \mathrm{C}$ data are lower and higher, respectively, than their projected values. The proposed structure does not consider the ambient water content, therefore after annealing at $100^{\circ} \mathrm{C}$ a more reliable picture of the intrinsic hydrogen concentration emerges: a very high hydrogen concentration of around $3 \times 10^{22} \mathrm{~g}^{-1}$ assigned to the $f^{\prime}$ content, and correspondingly, the $f^{\prime \prime}$ content has a value below $0.3 \times 10^{22} \mathrm{~g}^{-1}$. Under these considerations, the analysis indicates that the as-prepared material must have at least $90 \%$ of its intrinsic hydrogen content bound within about $45 \%$ of the silicon oxide-doped carbon matrix (i.e. the defect-laden silicon oxide-doped $f^{\prime}$ content).

While $N_{S}$ and $N_{\mathrm{H}}$ generally decrease with annealing, it seems the two quantities are fairly independent. As pointed out earlier, each display a different behavior at the higher annealing temperatures, i.e., the rate of hydrogen loss appears to abate somewhat, whereas the defect content continues to fall. Nevertheless, it is interesting that the bulk of the hydrogen content is found within the same proximity of the defect clusters. This reflects on the manner in which the $f^{\prime}$ and $f^{\prime \prime}$ contents are dispersed (see Fig. 13). The $f^{\prime \prime}$ contents comprises those parts of the film where a much lower concentration of paramagnetic broken bond defects resides. This picture seems favored in consideration of the starkly separated components in the proton $T_{2}$ relaxation profiles, which imply highly segregated relaxation domains within the material. On the other hand, the $N_{\mathrm{H}}$ value for the as-prepared material (based on HFS measurements of the film's hydrogen content) is larger than the bulk NMR value, but is not as large as expected in consideration of the projected $N^{\prime}$ value. Therefore, this scenario for the silicon oxide-doped $f^{\prime}$ and $f^{\prime \prime}$ contents is probably more nuanced than that implied by the relaxation data. 


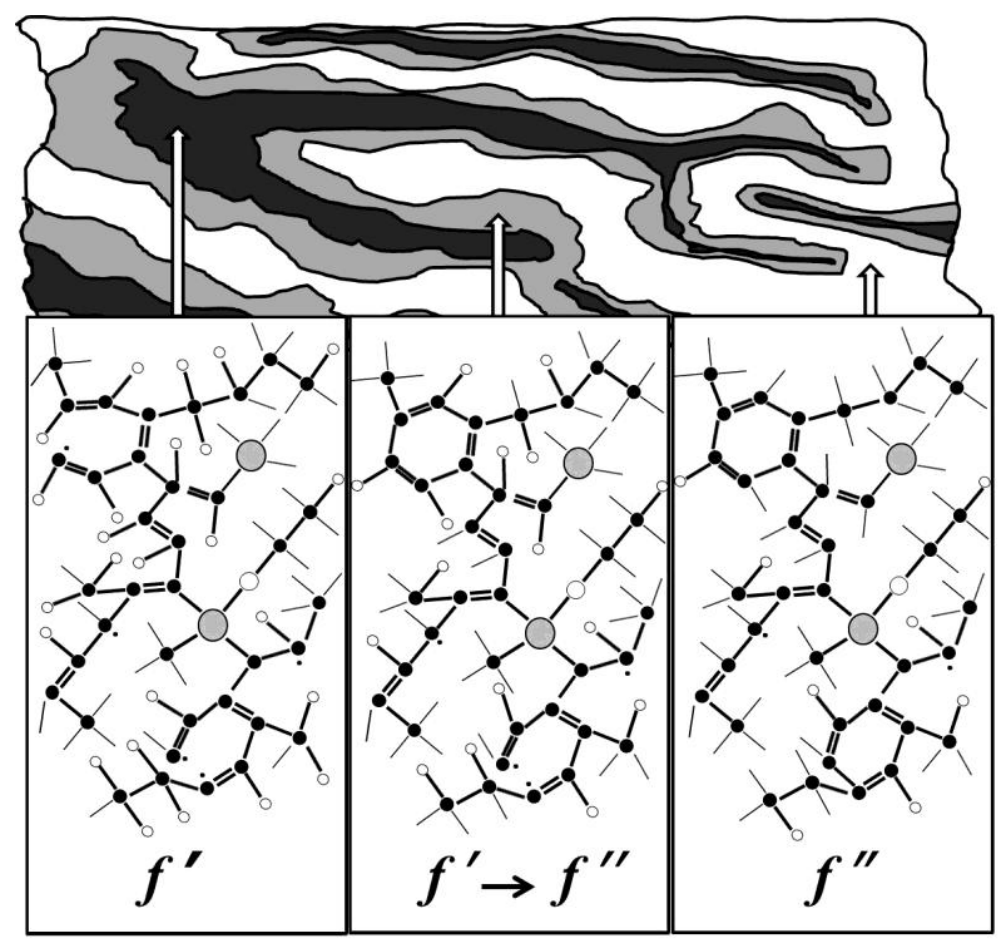

Figure 13. Illustration for the $20^{\circ} \mathrm{C}-300^{\circ} \mathrm{C}\left(f^{\prime} \rightarrow f^{\prime \prime}\right)$ structural evolution of a-C:H:Si:O. Legend: $\mathbf{C}=\bullet, \mathbf{S i}=\bigcirc, \mathbf{H}=\circ, \mathrm{O}=\circ$, and defect sites are indicated with dots.

\section{Conclusions and Summary}

The a-C:H:Si:O silicon oxide-carbon network exhibits long-range structural disorder, and is understood in terms of its basic $s p^{2}: s p^{3} \sim 65: 35$ carbon constituents interspersed randomly with $\mathrm{SiC}_{4-x} \mathrm{O}_{x}$ entities (most populated by $x=0$ and 1 ). The silicon oxide-carbon network, in a structural sense, is viewed here as a stage for defect and hydrogen distributions. The relaxation data indicate two distinct networks $\left(f^{\prime}\right.$ and $\left.f^{\prime \prime}\right)$, as defined solely by their defect and hydrogen distributions. It follows for the as-prepared material that a significantly large amount of protons and dangling bond defects are concentrated to within about $45 \%$ of the a-C:Si:O matrix. The remaining $55 \%$ of the material has the same $s p^{2}: s p^{3}$ carbon content, is not graphitic, and has a significantly lower concentration of hydrogen and defects.

Upon thermal treatment, the structure evolves towards a more thermodynamically favorable state. The first step (with the lowest activation energy) involves hydrogen effusion and emission. Associated with this structural reorganization is a moderate level of defect reduction. This is not highly evident in the $s p^{2}$ and $s p^{3}$ singular specie trends, but is nicely summarized within the $f^{\prime}$ and $f^{\prime \prime}$ data of Fig. 8. The second step occurs during higher temperature annealing $\left(150^{\circ} \mathrm{C}\right.$ to $\left.300^{\circ} \mathrm{C}\right)$, where hydrogen emission appears to lessen, as most of the more volatile atoms have left the 
material, and a marked increase in $s p^{2}$ content occurs, as well as a greater rate of defect annihilation. Although carbon $s p^{3} \rightarrow s p^{2}$ conversion is known to occur at higher annealing temperatures (where the activation energy requirements are more likely met), the increased $s p^{2}$ signal will also include contributions from $s p^{2}$ entities formed as a result of defect passivation during annealing, e.g., defect-sp $p^{2}+\mathrm{H}-s p^{2} \rightarrow \mathrm{H} \cdot+s p^{2}-s p^{2}$. Carbon defect-sp $p^{2}$ belong to a population of species that are very close to or are directly involved with paramagnetic defects, and as defects disappear the resonances of these nearby ${ }^{13} \mathrm{C}$ nuclei become increasingly observable. The implication here is that these NMR results may provide at least qualitative information regarding lower energy conversion of defect carbon states to $s p^{2}$.

Even though no evidence for significant clustering and ordering of $s p^{2}$-bonded carbon appears in this work, as this has been reported for a-C:H materials at higher annealing temperatures [13], XPS and NEXAFS data acquired while annealing a-C:H:Si:O under vacuum conditions, which will be the subject of a separate publication, indicate that two structural changes occur at elevated temperatures, namely clustering and ordering of $s p^{2}$ carbon and transformation of $s p^{3}$ - to $s p^{2}$ hybridized carbon (through the scission of $\mathrm{C}-\mathrm{H}, \mathrm{C}-\mathrm{Si}$, and $\mathrm{C}-\mathrm{C}$ bonds). While the present study provides clear evidence of the thermally-activated processes taking place in a-C:H:Si:O at low temperatures, additional experimental work at higher temperatures should be performed to elucidate other thermally-activated processes occurring in the bulk of this material, while enabling the comparison of NMR/EPR results with the outcomes of surface-sensitive analytical techniques (e.g., XPS and NEXAFS spectroscopy).

\section{Acknowledgements}

This material is based upon work supported by the Advanced Storage Technology Consortium ASTC (grant 2011-012) and the National Science Foundation under Grant No. DMR-1107642. F.M. acknowledges support from the Marie Curie International Outgoing Fellowship for Career Development within the 7th European Community Framework Programme under contract no. PIOF-GA-2012-328776. The authors would like to thanks Dr. C. Jaye, Dr. D.A. Fischer, Dr. P. Albrecht, and Dr. D.R. Mullins for their kind assistance with the NEXAFS measurements at the National Synchrotron Light Source. Use of the National Synchrotron Light Source, Brookhaven National Laboratory, was supported by the US Department of Energy, Office of Science, Office of Basic Energy Sciences, under Contract No. DE-AC02-98CH10886. We are grateful to Dr. F. Rose (previously at HGST, a Western Digital Company) for the X-ray reflectivity measurements. The NMR Facility at Hunter College is supported by an NIH Infrastructure grant (RR003037). We acknowledge Dr. J. Fontaine from École Centrale de Lyon for fruitful discussions. 


\section{References}

1. $\quad$ Stachurski, Z.H., On Structure and Properties of Amorphous Materials. Materials, 2011. 4(9): p. 1564-1598.

2. Hoffman, D.C., Bulk Metallic Glasses and Their Composites: A Brief History of Diverging Fields. Journal of Materials, 2012. 2013: p. 8.

3. Inoue, A. and A. Takeuchi, Recent development and application products of bulk glassy alloys. Acta Materialia, 2011. 59(6): p. 2243-2267.

4. $\quad$ Mort, J., Applications of amorphous materials. Physics in Technology, 1980. 11(4): p. 9.

5. $\quad$ Donnet, C., Erdemir, A., Tribology of Diamond-Like Carbon Films. 2008, New York: Springer.

6. Erdemir, A., Donnet, C., Modern Tribology Handbook. Tribology of Diamond, Diamond-Like Carbon, and Related Films. 2001, Boca Raton: CRC Press.

7. Robertson, J., Deposition Mechanisms for Promoting Sp(3) Bonding in Diamond-Like Carbon. Diamond and Related Materials, 1993. 2(5-7): p. 984-989.

8. Robertson, J., Gap states in diamond-like amorphous carbon. Philosophical Magazine B-Physics of Condensed Matter Statistical Mechanics Electronic Optical and Magnetic Properties, 1997. 76(3): p. 335-350.

9. Robertson, J., Diamond-like amorphous carbon. Materials Science and Engineering: R: Reports, 2002. 37(4-6): p. 129-281.

10. Robertson, J. and E.P. O'Reilly, Electronic and atomic structure of amorphous carbon. Physical Review B, 1987. 35(6): p. 2946-2957.

11. Sánchez-López, J.C. and A. Fernández, Doping and Alloying Effects on DLC Coatings, in Tribology of Diamond-Like Carbon Films, C. Donnet and A. Erdemir, Editors. 2008, Springer US. p. 311-338.

12. Dorfman, V.F., Diamond-like nanocomposites (DLN). Thin Solid Films, 1992. 212(1-2): p. 267-273.

13. Mangolini, F., et al., Thermally induced evolution of hydrogenated amorphous carbon. Applied Physics Letters, 2013. 103(16): p. -.

14. Scharf, T.W., et al., Mechanisms of friction in diamondlike nanocomposite coatings. Journal of Applied Physics, 2007. 101(6): p. 063521.

15. Neerinck, D., et al., Diamond-like nanocomposite coatings (a-C:H/a-Si:O) for tribological applications. Diamond and Related Materials, 1998. 7(2-5): p. 468-471.

16. Ferrari, A.C., Determination of bonding in diamond-like carbon by Raman spectroscopy. Diamond and Related Materials, 2002. 11(3-6): p. 1053-1061.

17. Ferrari, A.C. and J. Robertson, Interpretation of Raman spectra of disordered and amorphous carbon. Physical Review B, 2000. 61(20): p. 14095-14107.

18. Ferrari, A.C. and J. Robertson, Resonant Raman spectroscopy of disordered, amorphous, and diamondlike carbon. Physical Review B, 2001. 64(7).

19. Ferrari, A.C. and J. Robertson, Raman spectroscopy of amorphous, nanostructured, diamond-like carbon, and nanodiamond. Philosophical Transactions of the Royal Society a-Mathematical Physical and Engineering Sciences, 2004. 362(1824): p. 2477-2512.

20. Kaciulis, S., Spectroscopy of carbon: from diamond to nitride films. Surface and Interface Analysis, 2012. 44(8): p. 1155-1161.

21. Mezzi, A. and S. Kaciulis, Surface investigation of carbon films: from diamond to graphite. Surface and Interface Analysis, 2010. 42(6-7): p. 1082-1084.

22. Grierson, D.S., et al., Thermal stability and rehybridization of carbon bonding in tetrahedral amorphous carbon. Journal of Applied Physics, 2010. 107(3).

23. Lenardi, C., et al., Near-edge x-ray absorption fine structure and Raman characterization of amorphous and nanostructured carbon films. Journal of Applied Physics, 1999. 85(10): p. 71597167.

24. Osswald, S., et al., Control of $s p(2) / s p(3)$ carbon ratio and surface chemistry of nanodiamond powders by selective oxidation in air. Journal of the American Chemical Society, 2006. 128(35): p. 11635-11642.

25. Ferrari, A.C., et al., Determination of bonding in amorphous carbons by electron energy loss spectroscopy, Raman scattering and X-ray reflectivity. Journal of Non-Crystalline Solids, 2000. 266: p. $765-768$.

26. Paterson, M.J., An investigation of the role of hydrogen in ion beam deposited $a-C: N$. Diamond and Related Materials, 1998. 7(6): p. 908-915. 
27. Donnet, C., et al., Solid state $C-13$ and $H-1$ nuclear magnetic resonance investigations of hydrogenated amorphous carbon. Journal of Applied Physics, 1999. 85(6): p. 3264-3270.

28. Alam, T.M., T.A. Friedmann, and A.J.G. Jurewicz, Solid state C-13 MAS NMR investigations of amorphous carbon thin films - Structural changes during annealing. Thin Films: Preparation, Characterization, Applications, 2002: p. 277-289.

29. Alam, T.M., et al., Low temperature annealing in tetrahedral amorphous carbon thin films observed by C-13 NMR spectroscopy. Physical Review B, 2003. 67(24).

30. Bustillo, K.C., M.A. Petrich, and J.A. Reimer, Characterization of Amorphous Hydrogenated Carbon Using Solid-State Nuclear-Magnetic-Resonance Spectroscopy. Chemistry of Materials, 1990. 2(2): p. 202-205.

31. Carduner, K.R., et al., Solid State NMR Study of Carbon Bonding in Amorphous Hydrogenated Carbon Films. Applied Magnetic Resonance, 1991. 2(4): p. 647-653.

32. Cho, G., B.K. Yen, and C.A. Klug, Structural characterization of sputtered hydrogenated amorphous carbon films by solid state nuclear magnetic resonance. Journal of Applied Physics, 2008. 104(1).

33. Chu, P.K. and L.H. Li, Characterization of amorphous and nanocrystalline carbon films. Materials Chemistry and Physics, 2006. 96(2-3): p. 253-277.

34. Golzan, M.M., et al., Nmr Evidence for Strained Carbon Bonding in Tetrahedral AmorphousCarbon. Chemical Physics, 1995. 193(1-2): p. 167-172.

35. Iseki, T., et al., Structural analysis of Si-containing diamond-like carbon. Diamond and Related Materials, 2006. 15(4-8): p. 1004-1010.

36. Jager, C., et al., Structural-Properties of Amorphous Hydrogenated Carbon .3. Nmr Investigations. Physical Review B, 1994. 50(2): p. 846-852.

37. Kaplan, S., F. Jansen, and M. Machonkin, Characterization of Amorphous Carbon-Hydrogen Films by Solid-State Nuclear Magnetic-Resonance. Applied Physics Letters, 1985. 47(7): p. 750-753.

38. Lukins, P.B., et al., C-13 Nmr and Ftir Study of Thermal Annealing of Amorphous Hydrogenated Carbon. Carbon, 1993. 31(4): p. 569-575.

39. Pan, H.J., et al., Local Coordination of Carbon-Atoms in Amorphous-Carbon. Physical Review B, 1991. 44(13): p. 6741-6745.

40. Tamor, M.A., W.C. Vassell, and K.R. Carduner, Atomic constraint in hydrogenated "diamond-like", carbon. Applied Physics Letters, 1991. 58(6): p. 592.

41. Xu, J., et al., Structural characterization of ion-vapor deposited hydrogenated amorphous carbon coatings by solid state C-13 nuclear magnetic resonance. Journal of Applied Physics, 2014. 115(1).

42. Barklie, R.C., Characterisation of defects in amorphous carbon by electron paramagnetic resonance. Diamond and Related Materials, 2003. 12(8): p. 1427-1434.

43. Collins, M., et al., Characterisation of defects in thin films of hydrogenated amorphous carbon. Diamond and Related Materials, 2000. 9(3-6): p. 781-785.

44. Jones, B.J., et al., Nanostructure and paramagnetic centres in diamond-like carbon: Effect of Ar dilution in PECVD process. Diamond and Related Materials, 2008. 17(7-10): p. 1629-1632.

45. Ristein, J., J. Schafer, and L. Ley, Effective Correlation Energies for Defects in a-C-H from a Comparison of Photoelectron Yield and Electron-Spin-Resonance Experiments. Diamond and Related Materials, 1995. 4(4): p. 508-516.

46. Shames, A.I., et al., Defects and impurities in nanodiamonds: EPR, NMR and TEM study. Journal of Physics and Chemistry of Solids, 2002. 63(11): p. 1993-2001.

47. Mauri, F., B.G. Pfrommer, and S.G. Louie, Ab initio NMR chemical shift of diamond, chemicalvapor-deposited diamond, and amorphous carbon. Physical Review Letters, 1997. 79(12): p. 23402343.

48. Rose, F., et al., Complete characterization by Raman spectroscopy of the structural properties of thin hydrogenated diamond-like carbon films exposed to rapid thermal annealing. Journal of Applied Physics, 2014. 116(12): p. 123516.

49. Kester, D.J., et al., Sliding wear behavior of diamond-like nanocomposite coatings. Surface and Coatings Technology, 1999. 113(3): p. 268-273.

50. Neerinck, D., et al., Tribological properties and structural investigation of diamond-like nanocomposites. PROC INT SYMP TRENDS NEW APPL THIN FILMS TATF, 1996: p. 67-69.

51. Neerinck, D., et al., Diamond-like nanocomposite coatings (a-C:H/a-Si:O) for tribological applications. Diamond and Related Materials, 1998. 7(2-5): p. 468-471. 
52. Neerinck, D., et al., Diamond-like nanocomposite coatings for low-wear and low-friction applications in humid environments. Thin Solid Films, 1998. 317(1-2): p. 402-404.

53. Prasad, S.V., et al., LIGA Microsystems: Surface Interactions, Tribology, and Coatings. Journal of Manufacturing Processes, 2004. 6(1): p. 107-116.

54. Scharf, T.W., et al., Mechanisms of friction in diamondlike nanocomposite coatings. Journal of Applied Physics, 2007. 101(6): p. 063521-11.

55. Venkatraman, C., C. Brodbeck, and R. Lei, Tribological properties of diamond-like nanocomposite coatings at high temperatures. Surface and Coatings Technology, 1999. 115(2,Äỉ): p. 215-221.

56. Venkatraman, C., et al., Electrical properties of diamond-like nanocomposite coatings. Thin Solid Films, 1997. 308, Äi309(0): p. 173-177.

57. Venkatraman, C., et al., Diamond-Like Nanocomposite Coatings - A New Class of Materials, in Surface Modification Technologies IX, T.S. Sudarshan, W. Reitz, and J.J. Stiglich, Editors. 1996, The Minerals, Metals \& Materials Society.

58. Fukushima, E., Roeder, S.B.W., Experimental Pulsed NMR: A Nuts and Bolts Approach. 1981, Addison-Wesley Publishing Co., Inc.: Massachusetts.

59. Wagoner, G., Spin Resonance of Charge Carriers in Graphite. Physical Review, 1960. 118(3): p. 647-653.

60. Conway, N.M.J., et al., Defect and disorder reduction by annealing in hydrogenated tetrahedral amorphous carbon. Diamond and Related Materials, 2000. 9(3-6): p. 765-770.

61. Conway, N.M.J., et al., Reduction in defect density by annealing in hydrogenated tetrahedral amorphous carbon. Applied Physics Letters, 1998. 73(17): p. 2456-2458.

62. Grill, A., Meyerson, B., Synthetic Diamond: Emerging CVD Science and Technology. 1994, New York: Wiley. 91.

63. Blinc, R., et al., C-13 nuclear magnetic resonance and electron spin resonance of amorphous hydrogenated carbon. Journal of Physics-Condensed Matter, 1998. 10(30): p. 6813-6824.

64. Snape, C.E., et al., Quantitative reliability of aromaticity and related measurements on coals by $13 C$ n.m.r. A debate. Fuel, 1989. 68(5): p. 547-548.

65. Ripmeester, J.A. and C.I. Ratcliffe, Low-Temperature Cross-Polarization Magic Angle Spinning C13 Nmr of Solid Methane Hydrates - Structure, Cage Occupancy, and Hydration Number. Journal of Physical Chemistry, 1988. 92(2): p. 337-339.

66. Abragam.

67. Noack.

68. Alemany, L.B., et al., Cross Polarization and Magic Angle Sample Spinning Nmr-Spectra of Model Organic-Compounds .1. Highly Protonated Molecules. Journal of the American Chemical Society, 1983. 105(8): p. 2133-2141.

69. Jarman, R.H. and G.J. Ray, Direct Determination of Carbon Hybridization in Amorphous-Carbon Films Using C-13 Nmr-Spectroscopy. Journal of the Chemical Society-Chemical Communications, 1985(17): p. 1153-1154.

70. Finlay, G.R., et al., Si-29 and C-13 Magic Angle Spinning Nmr-Spectra of Silicon-Carbide Polymorphs. Journal of the Chemical Society-Chemical Communications, 1985(3): p. 159-161.

71. Segatelli, M.G., A.T.N. Pires, and I.V.P. Yoshida, Synthesis and structural characterization of carbon-rich SiCxOy derived from a Ni-containing hybrid polymer. Journal of the European Ceramic Society, 2008. 28(11): p. 2247-2257.

72. Schilling, F.C., T.W. Weidman, and A.M. Joshi, Solid-State Characterization of Polysilanes Containing the Sih Bond. Macromolecular Symposia, 1994. 86: p. 131-143. 